\title{
The Political Consequences of Franchise Extension: Evidence from the Second Reform Act
}

\author{
Samuel Berlinski ${ }^{1}$ and Torun Dewan ${ }^{2}$
}

August, 2010

\begin{abstract}
We use evidence from the Second Reform Act, introduced in the United Kingdom in 1867 , to analyze the impact on electoral outcomes of extending the vote to the unskilled urban population. Exploiting the sharp change in the electorate caused by franchise extension, we separate the effect of reform from that of underlying constituency level traits correlated with the voting population. Although we find that the franchise affected electoral competition and candidate selection, there is no evidence relating Liberal electoral support to changes in the franchise rules. Our results are robust to various sources of endogeneity. ${ }^{3}$
\end{abstract}

\section{OVERVIEW AND INTRODUCTION}

Several theoretical studies shed light on the relationship between franchise extension and policy outcomes, providing plausible connections between changes in the rules governing the eligibility to vote and incentives of policy makers leading to greater redistribution (Boix, 2003, 2001; Acemoglu and Robinson, 2000) or expansion of local public goods (Lizzeri and Persico, 2004). Empirical analysis (Aidt and Jensen, 2009; Lindert, 2004; Husted and Kenny, 1997) suggests a "growing consensus that the extension of the franchise contributed positively to the growth in government" (Aidt and Jensen, 2009, p19). ${ }^{4}$ From a political science perspective, however, a critical element of the link between franchise extension and policy outcomes is missing. In particular we know little about the political mechanism that relates changes in the franchise to the growth of government. In principle, policy changes caused by franchise extension could arise due to several

\footnotetext{
${ }^{1}$ University College London. Email: s.berlinski@ucl.ac.uk

${ }^{2}$ London School of Economics. Email:t.dewan@1se.ac.uk

${ }^{3}$ We thank Facundo Albornoz, Jim Alt, Ernesto Dal Bo, Gary Jacobson, Jouni Kuha, Valentino Larcinese, Thomas Pluemper, Stephanie Rickard, Ken Scheve, Ken Shepsle, and seminar participants at APSA, Berkeley, ECPR, Essex, and Yale for helpful comments. We thank Cheryl Schonhardt-Bailey and James Robinson for sharing their data. We thank STICERD for financial assistance and May Chu and Brenda van Copenolle for excellent research assistance.

${ }^{4}$ At the same time the link between franchise reform and fiscal policy appears not to be direct: Aidt et al. (2009) show a non-monotonic relationship between franchise extension and the probability of adopting income tax; Lindert (1994), assesses the impact of variation in electoral rules across countries and finds little evidence that social spending increased before 1920; Scheve and Stasavage (2008) show tax rates were flat during the late nineteenth and early twentieth century, rising sharply as countries mobilized for war; and Aidt and Jensen (2009) and Husted and Kenny (1997) show that institutional tax raising capacity is an important conditioning variable.
} 
factors, inter alia, the voting behavior of newly enfranchised citizens, differences in party competition, candidacy and incumbency effects, or differences in agenda-setting and voting behavior of political elites.

Analysis of specific franchise extensions can help isolate these different effects. An important test case is the Second Reform Act in the United Kingdom. This extended the franchise to the unskilled urban population, with an overall increase in the 1867 voting population in England, Scotland, and Wales of $97 \%$. To analyze the impact of franchise extension on political outcomes in the United Kingdom during this period, we exploit the constituency level variation in the voting population that arose from the reform. There are few studies that analyze the impact of franchise extension at such a local level. ${ }^{5}$ Doing so allows us to understand the political mechanisms at work and provides new insights into rival hypothesis about the underlying causes and effects of franchise extension.

Historians of the period have been puzzled by the exact nature of the suffrage reforms. Most have seen extension of the franchise as related to competition between the Liberal and Conservative parties and tensions between their two great leaders, Disraeli and Gladstone. In general, political scientists concur with the notion that elites anticipate the competitive effects of any change to the rules governing eligibility to vote. There are, however, several reasons why franchise extension during this period is unlikely to be related to inter-party political calculations: the Second Reform Act of 1867 preceded the election of the first ever unequivocally Liberal administration in 1868 and ushered in a period of radical reform; the Reform Act was more extensive than a Liberal measure that had failed to pass in the Commons in the previous year; the Act was, however, introduced by a minority Conservative government, whose main constituency was the rural voters; finally, and critically, the reforms increased the voting population in precisely those urban areas likely to be sympathetic to the Liberals.

The argument is nicely summarized by Acemoglu and Robinson (2000): "as the result of the split over the Corn Laws, support for the Conservative party was essentially concentrated in rural areas, with Tory landowners exerting substantial control over the electorate in the absence of a secret ballot. The reform measure passed under Disraeli increased the voting population by only 45 percent in counties, compared to 145 percent in the boroughs, effectively ensuring a Conservative defeat in the following elections."

The outcome of the 1868 general election- a comfortable victory for the Liberals- can then be considered as evidence against the view that franchise extension arose due to such internal party political considerations and suggests, instead, that franchise extension originated as a response to popular pressure for reform. This claim would be stronger if the extension of the franchise, initiated by the Conservative government, could be causally linked to the election of a Liberal government

\footnotetext{
${ }^{5}$ An exception is Aidt et al. (2009) who look at the impact of changes in the local government franchise in the UK in the 19th century, showing a non-monotonic relationship between inequality and the provision of local goods.
} 
with a reforming agenda. Although the extension of the franchise was correlated with Liberal success, and hence the introduction of their radical agenda, it is as yet unproven that the change in rules concerning voter eligibility contributed to that success. Whilst we cannot directly observe the counterfactual - the electoral outcome had the electoral rules established in 1832 remained in place- a careful identification strategy provides a second best solution that allows us to understand the impact of change in the voting population.

Three features of the Second Reform Act allow us to identify the impact of the change in the rules concerning eligibility to vote on the political outcomes of subsequent elections. Firstly, the extent and impact of the Second Reform Act was largely unanticipated. Indeed Disraeli's strategy was famously described by Lord Cranborne, a senior minister who resigned from cabinet over the issue, as a "leap in the dark". Secondly, we show that there was a large amount of variability with regard to the effect of the change in the electoral rules on the eligible voting population at the constituency level. Thirdly, and unlike previous and later reforms, the extension of the franchise in 1867 was unaccompanied by other constitutional changes that would confound any attempt to isolate the causal impact of reform.

For most of our analysis, we look at a sample of boroughs where franchise reform was not associated with any change in the constituency boundaries or the number of parliamentary seats to be filled between the general elections of 1865 and 1868. Exploiting the constituency level variation in the impact of franchise reform in this sample - to separate its effect from that of underlying constituency level traits correlated with the voting population - and controlling for a national swing, we thus isolate the effect on Liberal support that is due to the impact of the extension of the franchise from that of other factors that may have lead to the Liberal victory in 1868 . We then ask whether the constituency level expansion of the franchise due to the new electoral law introduced in 1867 provided a source of advantage for the Liberal Party.

We first explore whether the differences in the constituency level franchise were related to change in the structure of party competition between the Liberals and Conservatives. Before the Second Reform Act many seats were uncontested. In these constituencies no ballots were cast; either one party received all seats unopposed, or both parties agreed the share of seats to be allocated. A possible source of Liberal advantage is that, under the new franchise rules, they could contest a larger share of constituency level seats. Unsurprisingly we find that the number of uncontested seats declines sharply, and more so in the constituencies most affected by reform. Moreover, we find that, overall, there is an increase in the ratio of candidates to seats and that this is due to greater contestation by Liberal candidates. The evidence also suggests that incumbents were less likely to run in areas most affected by reform.

However, and despite differences in the nature of party and candidate competition at the constituency level, we find no evidence suggesting that the direct outcome of the election was related 
to franchise reform. Neither the differences in the Liberal share of votes or the percentage of seats won by Liberal candidates can be explained by changes to the rules governing the eligibility to vote. Thus, our analysis suggests that the outcome of the election in 1868 - a victory for the Liberal Party under Gladstone- was incidental to the major reform in the voting franchise that took place in 1867.

Extending our analysis, we explore possible causes for our null findings. The first involves measurement error that arises because we do not directly observe the relevant population - those eligible to vote under the new rules - rather a subset of the eligible voting population who registered to vote. As highlighted in the important study by Davis and Tanner (1996), the actual number of registered voters in each constituency reflected local difficulties in registering the newly enfranchised population. Moreover, the details of the new franchise rules, which included a residency requirement and excluded certain types of dwellings, left ambiguities to be resolved by local judges and administrators. If, as a result, the ratio of registered voters to population is not constant between the two elections analyzed, the resulting measurement error may bias downwards our results.

A second cause of our null findings relates to reverse causality that may bias downwards our estimates of a marginal increase in the voting franchise in a given constituency. It is possible that, at the margin, the reforms were administered in such a way that their effect was less in those areas where Liberal support was growing more quickly. We should not overemphasize this issue. By itself, extension of the franchise is a blunt tool for seeking political advantage. It was not possible for Disraeli to cherry-pick conservative voting groups to be given the vote. Indeed, it is more likely that in order to assuage social unrest, the franchise may have been allowed to grow faster in places were social unrest and possibly liberal support was growing faster. If this is the case our estimates will be biased upwards. Nevertheless, and to deal with both the issue of measurement error and reverse causality, we instrument the change in the level of enfranchised voters and we study pretrends in the outcomes of interest. Doing so yields no systematic change in our results: we find no evidence to support the view that the Liberals became stronger in those areas most affected by electoral reform.

A third issue involves our sampling strategy. The main effect of the Second Reform Act was to introduce into the franchise a large block of new voters. To identify the effect of this change we focus mainly on those boroughs unaffected by boundary changes or changes in the number of seats. Since the decision to leave the contours of a district (and the number of seats available) was politicized, it is possible that different samples would yield different outcomes. We deal with this in several ways: we show that the main (average) outcomes of interest do not vary systematically prior to 1868; thus the population of constituencies where the only thing that changed is the number of eligible voters, is on average, and on our key indicators, the same as the population of 
constituencies that received additional changes. In our regression analysis we also use different samples and include interaction effects. This reveals no discernable difference to our estimates.

A final hypothesis for explaining our null findings is that Conservative incumbents may have adapted their views in order to appeal to their new electorate. To explore this issue we analyze the parliamentary voting behavior of Members of Parliament (MPs) in this period. In particular, we focus our attention on the Abolition of Church Rates Bill introduced in the parliamentary sessions of 1866 and 1867. Church rates were personal taxes on property owners that were used to support the established church. There was popular agitation to abolish them and support for abolition was divided along party lines. Due to the constraints of the parliamentary timetable, we observe MPs' voting behavior before and after the Second Reform Act bill was introduced into parliament. We find no evidence suggesting that the intensity of the forthcoming expansion of the franchise was related to changes in voting behavior on the Abolition of Church Rates Bill.

We begin our analysis in the following section by providing background information on the Second Reform Act. We then look at why the nature of the reform has puzzled historians of the period as well as contemporary political economists. In section 4 we describe our data. In section 5 we present our identification strategy. In section 6 we present our main estimates. Section 7 looks at the robustness of our results when analyzing different samples, taking into account possible endogeneity, and exploring possible medium run effects of the reform act. Section 8 discusses possible changes in MPs voting behavior that could have been caused by the forthcoming franchise extension. Finally section 9 concludes.

\section{Background: Electoral Reform And The Second Reform Act}

Elections in Britain in the Victorian period under investigation took place under the first-past-thepost voting system that is still in place. Whilst some constituencies were single-member districts, most constituencies elected two candidates and a few elected three and four. The constituency elections were contested by candidates who aligned with one of two major parties, the Conservatives and the Liberals. The Liberals brought together a loose coalition of Whigs, Radicals, and Peelites (a faction that had broken from the Conservatives) and by 1860 formed a cohesive parliamentary block. Following Lord Palmerston's death in 1865 the Liberals were lead by William Gladstone. For the immediate period preceding the elections of our investigation, Liberals had held the key ministries of government. However, between 1865 and 1868 the Conservatives formed a minority government, first under Lord Derby and then under Benjamin Disraeli.

The Representation of the Peoples Act, otherwise known as the Second Reform Act, was passed by Parliament on August 15th, 1867. As its name suggests it was the second major voting reform bill that transformed the political landscape in the Great Britain. The first major extension of the 
franchise in the UK took place in 1832. The Great Reform Act of that year introduced several measures that mitigated malaportionment: increasing representation in the industrialized cities, and taking away seats from the so-called "rotten boroughs" with small voting populations. The act also increased the male franchise to around 650,000.

The Second Reform Act, that became law in England and Wales in 1867, extended the franchise in the boroughs to all males over the age of 21 who were inhabitant occupiers, whether house-owners or tenants, and to male lodgers whose rent was at least $£ 10$ per year. A residence of at least one year in the borough was required and women were still unable to vote. In counties, the franchise was extended to holders of life interests, copyholds and leases of sixty years and more worth $£ 5$ per annum (from a previous threshold of $£ 10$ ) and to tenants occupying land worth $£ 12$ (from a previous threshold of $£ 50$ per annum). The Reform Acts for Scotland was delivered in 1868 . $^{6}$ The reforms were swiftly followed by the election of a new parliament in 1868 . This provides us with a unique window of opportunity for identifying the impact of franchise extension.

Later Reform Acts introduced the secret ballot (1872), placed the counties on an equal footing with the urban boroughs (1884), reduced the number of multiple member districts (1885), extended the franchise to all males (1918), and provided women with electoral equality (1928). The full time line of reforms since 1832 is provided in Figure 1.

Table 1 presents the number of registered electors in 1859, 1865, 1868 and 1874 for England, Wales, and Scotland in both boroughs and counties. ${ }^{7}$ It is clear that the Reform Act lead to an increase in the franchise not witnessed either before or after the 1868 election. From 1859 to 1865 the registered electorate in England, Scotland and Wales increased by $7 \%$ and from 1868 to 1874 by $12 \%$; this compares with a $97 \%$ increase between 1865 to 1868 . Overall the franchise included more than 1,000,000 newly registered electors. The increase was more marked in the more densely populated urban boroughs where the franchise increased (on average) by $152 \%$ with respect to a $47 \%$ increase in counties. Indeed historians have noted that the most striking feature of the Second Reform Act was the unexpectedly wide extension of the franchise in the boroughs, when compared to the counties.

The Reform Act brought into the franchise voters from previously unenfranchised income brackets. Who were the new voters? Mackenzie (1921) and Bowley (1937) estimate the income of the head of the household at median, quartile and lowest decile of the income distribution in 1860. Mackenzie (1921) also provides estimates of household budgets for a typical family (man, wife, and 3 schoolchildren) which include the amount paid for rent. We present this information in Table 2 which shows that the annual income of a head of household in the upper quartile of the income

\footnotetext{
${ }^{6}$ Ireland had a reform act in 1868 but unlike in England, Scotland and Wales the impact of the reform on registered voters was marginal.

${ }^{7}$ These figures exclude the electors registered in the university constituencies which were allowed to vote both in the university constituency and in their town of residence
} 
distribution was more than $£ 70$; typically he was a semi-skilled worker (e.g, a brick-layer) and paid an annual rent in excess of $£ 10 .{ }^{8}$ The annual income of the head of household in the lower quartile was around 60 percent of that in the upper quartile; this would typically be the income of an unskilled worker (e.g., brick-layer laborer) and paid an annual rent in excess of $£ 6$. At the median of the income distribution the rent paid was close to $£ 8$. Although the calculations are (obviously) rough, given the data limitations, they help us to illustrate the type of households that gained the vote under the new franchise: it is clear that the extension of the franchise gave the vote to urban unskilled workers. ${ }^{9}$

However there were important qualifications. An aim of the Reform Act was to disqualify the "feckless". Paupers and those who did not satisfy the residency requirement were not entitled to vote. In addition, the rules initially excluded those who did not pay their own rates from the franchise. Payment of rates was seen as a signal of personal virtue, the possession of which was deemed a necessary condition of being granted the vote. Prior to the Second Reform Act, landlords were able to pay rates on their tenants behalf. This system of "compounding" eased administration on levying rates on houses that consisted of separate units the occupiers of which paid rents to a landlord. Hodgkinson's amendment to the original bill, in principal, abolished the system of compounding - henceforth, those eligible to vote were required to pay their own rates directly- but it did so only for occupiers who rented a house rather than a room or apartment. Thus, whereas some potential voters were excluded directly, the partial abolition of compounding introduced of ambiguity into the system that could only resolved by local magistrates. ${ }^{10}$ The net effect was what Davis and Tanner have called a "paradoxical and capricious system, still literally exclusive in that it denied many men the vote, but not selective in the way that its creators, anxious to limit the vote to those sharing Victorian norms of respectability, had intended."

\section{IntERPRETING AND UndERSTANDING THE SECOND REFORM ACT}

The Second Reform Act of 1867 was introduced by the Conservative government lead by Lord Derby, though most historians view Disraeli as its prime architect. Electoral reform had been considered for some time before the passing of the 1867 reform. Indeed a reform bill proposed by the Liberals lead by Earl Russell had been defeated by a coalition of Conservatives and Liberals opposed to reform in $1866 .{ }^{11}$ The fact that the reform bill of 1867 was introduced by a minority Conservative government, supported by backbench Conservatives, and that the reforms lead to a

\footnotetext{
${ }^{8}$ At the time 1 pound $=20$ shillings and 1 shilling $=12$ pence.

${ }^{9}$ Those in the lowest decile of the income distribution (the agricultural laborers) were only enfranchised in 1884.

${ }^{10}$ Compounding was partially reintroduced in 1869 under the Poor Rate Assessment and Collection Act.

${ }^{11}$ Earl Russell also failed to pass an electoral reform bill in 1860. Interestingly, neither Disraeli or Palmerston mentioned electoral reform in their electoral addresses in 1865. The death of Palmerston -elected as Prime Minister after the 1865 election- changed government policy and lead the Liberals to put the issue back on the table (Seymour, 1915).
} 
far greater increase in the franchise than would have been possible had the original Liberal reforms passed, has puzzled historians and commentators of the time.

The first, and simplest, view to consider is that Disraeli, the key architect of the Reform Act, pursued this course of action as he believed the Conservatives could (at best) reap rewards or (at worst) be left unaffected by implementation of the proposed voting reforms. Nineteenth century commentators such as Bagehot, for example, explained the reform as part of Disraeli's vision of a 'Tory Democracy' that would appeal to the conservative instincts of the British working classes. So Disraeli's strategy can be seen as part of his grander vision of one-nation conservatism: an attempt to build a majority Conservative party that appealed to different elements of British society (Himmelfarb, 1966). A related view is that Disraeli hoped to secure an electoral advantage by introducing an inevitable reform that allowed him to claim credit amongst newly enfranchised voters whilst exploiting divisions within the Liberal party over the issue. Further, in outsmarting his erstwhile rival Gladstone by passing a more radical bill than the Liberals had been able to, he hoped to reveal deficiencies in Gladstone as leader and parliamentarian (Jenkins (1996)). This view is given further credence by Maclean (2001) who suggests that, whereas Disraeli may not have been able to foresee the effects of reform, by "dishing the whigs", in passing a more radical reform, he ensured Tory backbench support.

The immediate electoral outcome in 1868, a victory for the Liberals, casts doubt on the hypothesis that the Tories benefited electorally via the inclusion of new voters in the franchise. Yet the historical evidence does not suggest either that the unskilled workers who voted for the first time in 1868 systematically favored the Liberals: Gash (1953) highlighted the essentially conservative character of the Victorian electorate; whereas Vincent (1968) showed that the social basis of voting behavior was underdeveloped in this period, with voters casting their ballots on local and symbolic issues. Thus, although members of Disraeli's government were horrified at the thought of expanding the Liberal voting base, it was not clear at the time that the extension of the franchise would have this effect. Whilst some historians believe that the sympathies of the newly enfranchised workers lay with the Liberals (see, for example, Whitfield (2001), p239), Disraeli's faith in the inherently conservative credentials of the new working class voters was not necessarily misplaced.

An alternative hypothesis relates extension of the franchise to external threats to the established political order, rather than inter-party disputes. Acemoglu and Robinson (2000) analyze the political economy of franchise extension and offer a compelling account of how franchise extension relates to fiscal redistribution. In their model, largely motivated by the Second Reform Act, an elite facing the threat of social revolution, has incentives to raise taxes to levels desired under a democracy. The ability of workers to extract concessions is transitory and arises only in periods of economic growth. An elite is thus unable to credibly commit to a redistributory tax policy when growth is stochastic and so are unable to assuage unrest. Extension of the franchise allows for a durable 
compromise in which the wealthy can make credible commitments of moderate redistribution that would dampen agitation for more radical economic reform. According to this view, events such as the Hyde park riots in 1866 and 1867 -in which supporters of the Reform League were involved in violent clashes with the police- were critical in shaping political incentives during this period, and forced an elite sceptical about reform to nevertheless embark upon the path of enfranchising the working classes.

Acemoglu and Robinson's theory brings together several disparate parts of this Victorian puzzlethe fact that the reform bill was passed by a Conservative government, and that the election was won by a reforming Liberal party, who arguably went on to transform British society with a series of radical measures. The critical piece of the puzzle is the fact that the reforms were designed to increase the vote share disproportionately in urban boroughs relative to the counties, despite the fact that the latter provided the bedrock for Conservative support. The authors argue that, due to this feature of the reform, the change in the franchise rules could only have benefited the Liberals. Thus the change in the rules can not plausibly be connected to electorally motivated considerations by the architects of the reform. Moreover, an immediate glance at the data provided in Table 1, that highlights the predominant impact of the reforms in the boroughs, tends to support the hunch that Liberal success was likely attributable to the precise nature of the reforms. Analyzing the immediate electoral outcomes can shed light on this issue. If the immediate electoral outcomes can be shown to be both beneficial to the Liberals and causally related to the introduction of the Second Reform Act then, indeed, it provides powerful supporting evidence for Acemoglu and Robinson's theory.

A central aim of our study is to explore which mechanism links franchise extension to change in political outcomes. Whilst it is implausible that the changes to the franchise rules can have had no effect, there are numerous mechanisms via which they might have impacted on British political development. The first and most obvious is that already discussed: Liberal success in 1868 may have been due to the incorporation into the franchise of low skilled workers with an average income lower than that found in the pre-existing franchise. Thus, fixing all aspects of competition between the Liberals and Conservatives, the inclusion of a new block of voters may, in and of itself, account for the immediate political outcomes. But of course, the parties responded to the new situation: the Liberal party may have been attracted by the prospect of competing in constituencies where previously the Conservatives had run unopposed; or increasing its share of constituency level candidates. For example Cox (1987), p69, discusses the aggregate increase in party competition during the period, as previously uncontested seats became open to competition, and the number of candidates increased. The question arises to what extent these changes can be seen as causally related to the impact of the Second Reform Act. 
Another avenue by which the reforms might impact on political outcomes is in providing incentives for parties to put forward different types of candidates, as changes in candidacy provides a mechanism by which the parties could credibly appeal to their new electorate. Most of the key organizational changes, such as the setting up of National Union of Conservative and Constitutional Associations (1867), and the National Liberal Foundation (1877), that affected the selection of local candidates, came too late to affect the immediate 1868 election; (though later on we present some evidence that organizational changes made by the Conservatives did impact on the 1874 election). Nevertheless, in light of the new electorate, the decision as to which candidates to run, and in which constituency to run them, took on renewed importance. In sum, a close investigation of the data from the Second Reform Act may then reveal subtle channels via which suffrage reform affected the political development of the United Kingdom. By looking at a wide range of outcomes concerning party and candidate competition, as well as the immediate electoral outcomes, we can ask what effects, if any, did franchise extension have on the political outcomes of the day.

A further aim of our study is to use the data from this period to shed light on the effect of franchise reforms on political representation. To what extent did this important Act lead to a system of oneman-one -vote in the United Kingdom? Historians have questioned the extent to which the Second Reform Act lead to an equitable distribution of votes amongst the eligible franchise. A particular problem, nicely summarized by Davis and Tanner (1996), p37, involved the registration of voters:

"a system geared to the registration of relatively small electorates was overwhelmed by the steady growth in the number of voters between 1867 and the eighteennineties, with the result that, however generous the law and however flexible the registration authorities, large numbers of potential voters slipped through the net."

A related concern involves Hodgkinson's amendment, that abolished the system of compounding whereby a landlord paid rates on his tenants behalf, as mentioned earlier. The new rules required house occupiers to pay their own rates and thus be listed separately as ratepayers. From these lists were then drawn the voting registers. In practice however, and due to ambiguities in Hodgkinson's amendment, in particular over what constituted a "dwelling house" under the new system, considerable discretion was handed to local barristers who oversaw the drawing up of local registers and this may in part explain the variance across constituencies in the number of registered voters. Whilst we do not address directly the extent to which the registered constituency level electorate represented the eligible voting population we can - by deploying a range of empirical strategies - control for local effects in assessing the impact of the reform on political outcomes. We can thus address directly the central question: did constituency level variation in the impact of the new franchise rules have a systematic impact on the political outcome of the reforms? 


\section{Data AND Descriptive Statistics}

Our data is gathered from Craig (1989), British Parliamentary Election Results, 1832-1885, which provides, for all national elections and by constituency, information on: number of seats, boundary changes, registered voters, name of candidates running, party of candidates, and votes per candidate. We also make use of the national population census 1861 and 1871 as reported in Vincent and Stenton (1971), McCalmont's Parliamentary Poll Book.

In order to identify the impact of the franchise extension we must be able to isolate its effect from other possibly confounding institutional factors. Whilst the extension of the franchise in 1867 coincided with a level of redistricting -some constituencies which previously had two Members of Parliament were reduced to one, or increased to three, some constituencies were eradicated, whilst others merged- unlike in 1832, in most constituencies the only major district level change was the increase in the franchise. Our focus on this period thus allows us to separate the effect of franchise extension on political behavior from other possibly confounding effects at the constituency level, in a way that an analysis of the earlier and posterior Reform Acts cannot.

Table 3 provides details of the total number of constituencies and seats in England, Scotland and Wales during the $1859,1865,1868$, and 1874 general elections as well as changes that arise during this period of reform (see, Craig (1989)). There were a total of 349 constituencies and 546 seats in the 1868 election with 304 constituencies appearing in all four elections. The difference between these numbers is explained by the fact that some constituencies were either newly created or defranchised during the period of analysis. From those constituencies that appear in all four elections only 43 experienced changes in the number of seats. Finally, there are 113 boroughs (with a total of 171 seats) and 60 counties (with a total of 95 seats) that do not experience either changes in seats or boundaries and appear in all four elections. Whilst most of our results rely on this restricted sample, that allows us to isolate the effect of changing the franchise rules from other institutional factors, we also show that our main results are robust to the inclusion of a broader range of constituencies.

In the period of study, the nature of political competition was remarkably different in counties and boroughs. As explained by Hanham (1959), p7: "village and tenant farmers generally voted along with their landlord not only because it was the accepted custom, but also because in everyday life the ordinary tenant was consciously dependant on the goodwill of his landlord". In fact, political competition was so weak in the counties that in 1865, for example, 67 percent of counties' constituency MPs were elected unopposed (i.e., without votes being cast). By contrast, in 1865 only 39 percent of borough MPs were elected unopposed. It was also the case that the different nature of electoral reform in boroughs and the counties had differential effects on the type of voters who were newly enfranchised. For these reasons we focus our main analysis in the boroughs. We show results for the counties in our robustness checks. 
Figure 2 (Panel A) presents kernel densities for the logged difference in the registered voters between 1865 and 1868 for the sample of boroughs without changes in boundaries and seats. An immediate and important observation is the wide variance in the effect of franchise extension in these constituencies. In some boroughs the changes in the voting rules had little discernible impact on the number of eligible voters, whereas in others the size of the (registered) electorate increased considerably. Adopting the language of the experimental literature- we can view the extension of the franchise as a 'treatment' that varies in intensity, ranging from (just below) 0 to (just over) 2 with an average around 1 . There are also substantive cross-sectional differences in the proportion of the population in a given constituency registered to vote in 1865 and, particularly, in 1868 . This is described in Figure 2 (Panel B) that presents density estimates of proportion of registered electorates to population per Borough in 1865 and 1868.

Table 4 provides further information on characteristics determining larger changes in electoral registration. We first examine how the franchise extension in 1867 relates to the (logarithm of) registered electorates in 1832. In column 1, we observe that the growth in voter registration is negatively and strongly correlated with the level of registered voters in 1832 . In column 2 , we add changes in the population size from 1871 to 1861 and find similar results. In columns (3) and (4), we look at the effect of the log of the level of population in 1861. The results in this case are also negative but less strong. In columns (5) and (6), we include both the log level of the electorate in 1832 and population in 1861. Ceteris paribus, the electorate grew slower where the (log of) registered electors in 1832 was larger and faster where the (log of) population 1861 was larger.

Constituency level voting behavior in Victorian Britain was affected by the menu of choices on offer, that in turn reflected the strategic calculations made by parties. In the 1868 election some constituencies were single member districts, some had two members, and a few retained three and four members. An immediate political measure that we observe is the number of contested seats. In 1865 and 1868 it was still the practice that, in some constituencies, Liberal or Conservative candidates would run unopposed. And in some multi-member districts the division of seats was agreed between the major parties before hand. As our results show this aspect of political collusion decreased sharply with the passing of the Second Reform Act. We investigate whether the share of uncontested seats in a constituency, which provides an indirect channel by which the extension of the franchise can shape the electoral outcomes, is causally related to the franchise extension. In addition, we assess whether the reform affected the number of candidates running per seat in a given constituency. Furthermore, we look at whether there was a relative increase in those running under the Liberal party label.

In our main analysis we concentrate on the constituency level impact of reform on electoral outcomes. We start by looking at two indicators of Liberal strength that are directly related to the behavior of the voting population. First, we look at the proportion of constituency level seats won 
by the liberal party. Second, for those constituencies where the elections were not unopposed, we look at the share of the liberal vote. ${ }^{12}$ Finally, we analyze voter turnout by looking at the average number of votes per seat over the number of registered electors.

Our analysis also looks at the issue of candidate selection. First, we explore the ratio of incumbents running to seats available in each constituency, and, disaggregating further, we study the proportion of Liberal incumbents who run again in the same electoral district. ${ }^{13}$ Following the same logic, we also look at the share of candidates who lose in the previous election but who stand again in the same constituency.

Table 5 provides summary statistics on the outcomes we have described for our sample of boroughs (without changes in seats and boundaries) during four national elections (1859, 1865, 1868 and 1874). The average constituency more than doubles in size between 1865 and 1868. During the same period the average Liberal vote-share increases from $63 \%$ to $66 \%$, and the share of Liberal seats increases by 4 percentage points from $73 \%$ to $77 \%$.

Turning to the competitiveness of the constituency races in our sample of boroughs, $37 \%$ of constituencies returned candidates without any votes being cast in 1865, whereas in 1868 the percentage of uncontested seats falls sharply to $23 \%$. The candidate to seat ratio also increased across the period, and in particular from 1.51 to 1.70 in the elections immediately either side of the Second Reform Act. The average Liberal candidate to seat ratio increases accordingly, from 0.97 to 1.12.

The share of incumbents who run increases from $57 \%$ to $67 \%$ and we observe that this increase is also true of Liberal incumbents: $40 \%$ of Liberal candidates were sitting incumbents in 1865, and this increases to $53 \%$ in 1868 . The rate of retention of losing candidates is higher: only $5 \%$ of candidates in 1865 had lost the same seat in the previous election and this increases to $7 \%$ in 1868 , with a similar rate of increase seen amongst losing Liberal candidates.

Whereas Table 5 provides summary statistics on our key outcomes for our sample of boroughs without changes in seats and boundaries, it is possible that, due to the political nature of the decision to leave boundaries and seats unaltered, this sample has particular properties. In particular, a natural suspicion is that Disraeli chose to leave the boundaries and magnitude of a district unchanged when he anticipated that the Liberals would then gain little in the next election, but to change either boundary or magnitude (or both) where he thought he could save Tory seats. Were this so then we would be unable to make any causal inference based on estimates from this sample.

\footnotetext{
${ }^{12}$ From the 452 election results we analyze (i.e., 113 constituencies over 4 national elections) a small number of elections (16 in total) were void after petitions. Craig (1989) reports votes cast in the original election and the winner as determined by electoral tribunal. We follow this procedure in assigning seats and votes to parties. However, in some cases a new election was run, usually at a much later date. In such cases we keep the results of the original election.

${ }^{13}$ Our incumbency measure does not adjust for the results of by-elections.
} 
To avert the suspicion that the sample of boroughs with no changes to either boundaries or seats is biased against the Liberals - a suspicion that arises due to the disputes between historians raised earlier- we compare our main outcomes of interest for the 1865 election across these different groups of constituencies. In particular, in Table 6, we draw comparisons between our baseline sample shown in column 1, that includes only those constituencies without boundary or seat changes, and two other samples: column 2 shows a sample that includes those constituencies with boundary changes but excludes those with seat changes; and column 3 shows a sample that includes those constituencies that experienced both seat and boundary changes.

Table 6 confirms that the Liberals were not systematically disadvantaged in those boroughs with boundary or seat changes. Indeed, if anything, the opposite is true: the average Liberal share of in 1865 is at least as large in the sample with no changes to boundaries or seats when compared to either of the other samples. For example, the average Liberal vote share in constituencies without boundary or seat changes is $63 \%$, whereas in the sample that consists of those boroughs with either boundary or seat changes it is $52 \%$. A simple difference in means test fails to reject the null hypothesis of no difference on average between our baseline sample and a sample that includes those constituencies with boundary changes but excludes those with seat changes. The difference in means between our baseline sample and that which includes those constituencies that experienced both seat and boundary changes is statistically significant at conventional levels. In sum, Table 6 shows that, if anything, the initial conditions in 1865 in the sample of seats that were left unaltered, and where the inclusion of a new tranche of voters was the main and only reform of 1867, were relatively sympathetic to the Liberals.

With regard to our other outcomes of interest we find significant differences between our baseline sample and one which includes those constituencies that experienced both seat and boundary changes: the share of incumbents running is on average smaller in the former; whereas the candidate to seat ratio, and the Liberal candidate to seat ratio is on average higher in the former. The fact that the constituencies with no boundary or seat changes had a relatively higher ratio of Liberal candidates to seats adds further evidence that those constituencies left unaltered were not those were the Conservative were relatively stronger.

Taken together, the basic statistics with regard to the outcomes in 1868 reveal that the change in the electoral rules accompanied an increase in political competitiveness and a corresponding increase in the average constituency level share of Liberal candidates, seats, and votes. In assessing different samples with respect to these outcomes in 1865 we do not find major differences. This then allows us, in what follows, to focus attention on the sample of constituencies where the only change that occurred between 1865 and 1868 was the introduction of a new tranche of voters. In the absence of other confounding changes to the rules, we can them analyze whether there is any causal relation 
between the change to the franchise and the key political outcomes of interest. In the following section we discuss our empirical strategy for dealing with other possible confounding factors.

\section{Empirical Strategy: Identifying the EFFECT of Franchise Extension on Political Outcomes}

To understand how political outcomes are causally related to the change in rules governing the eligibility to vote, we need to isolate the effect of a change in the franchise from other possibly confounding factors. Although franchise extension was applied nationally and simultaneously in all constituencies, the magnitude of the change at the constituency level reflects local conditions. In particular the local impact of a change in the electoral law is related to the constituency level distribution of income and housing in 1867. In estimating the causal effect of franchise expansion on political outcomes we face the problem that the change in franchise is systematically related to a set of constituency level characteristics that are likely to have an independent effect on political outcomes. Without controlling for these confounding factors, our estimates are likely to be biased and inconsistent.

As long as this differential impact of the reform on franchise levels is driven by community characteristics that are fixed overtime (or that vary slowly), we can measure the impact of franchise extension by comparing the differences in outcomes between communities where franchise levels vary by different amounts. Thus, including a constant to control for the national trend in liberal support, we estimate the following benchmark model for constituency $j$ at time $t$ :

$$
\triangle Y_{j t}=\alpha_{0}+\beta_{1} \triangle \log \left(R_{j t}\right)+\epsilon_{j t}
$$

where $Y_{j t}$ is one of our outcomes of interest and $\triangle Y_{i j t}$ represents the difference between 1865 and 1868 in this indicator; $\triangle \log \left(R_{j t}\right)$ is the difference in the log of constituency level registered voters between 1865 and 1868; and, finally, $\epsilon_{i}$ is a random error term. ${ }^{14}$

If the franchise level is the ratio of registered voters to the relevant constituency population then, provided that the population remains fixed or its change is uncorrelated with changes in $R_{j t}$, equation (1) is similar to regressing $\triangle Y_{j t}$ on the log difference in franchise levels. Because this may not be the case we also present estimates where we control for the change in the local population by including the (logged) difference between the population in 1861 and 1871, via the term $\triangle \log \left(P_{j t}\right)$. Including this term we then estimate

$$
\triangle Y_{j t}=\alpha_{0}+\beta_{1} \triangle \log \left(R_{j t}\right)+\gamma \triangle \log \left(P_{j t}\right)+\epsilon_{j t}
$$

\footnotetext{
${ }^{14}$ This model in first-differences is equivalent to one in levels with constituency fixed effects and a time dummy.
} 
The parameter of interest in equation (1) and (2) is $\beta$, the causal effect of changes in the franchise on electoral outcomes. ${ }^{15}$

Our empirical strategy goes a long way towards controlling for potential confounders in the relationship between franchise extension and political outcomes. It seems unlikely that, given the abrupt and unexpected change to the constituency franchise and the immediacy of the 1868 election, local trends in population, income, or wealth, could be systematically correlated with the expansion in the franchise. However, our identification strategy may still suffer from concerns about the exogeneity of our measure of franchise expansion.

The first concern relates to the registration process, when using registered electors as a measure of enfranchised voters we do not capture all citizens who are eligible to vote. In particular,

$$
R_{j t}=r_{j t} E_{j t}
$$

where $E_{j t}$ is eligible voters and $r_{j t}$ is the registration rate. If the registration rate is constant over time across constituencies, $r_{j t}=r_{j}$, then first differencing the logarithm of this expression eliminates the common error. However, if this error varies over time, we are subject to the traditional downwards bias even when measurement error is uncorrelated with $E_{j t}$. Moreover, the historical debate suggests, as we highlighted earlier, that some of the differences in registered electors were due to different interpretations of the franchise rules at the local level. If these differences are correlated with the growth or decline of liberal support at the local level our estimate will be biased and inconsistent.

The second issue concerns reverse causality. In order to assuage social unrest, the franchise may have been allowed to grow faster in places were social unrest and possibly liberal support was growing faster. If this is so then our estimates will be biased upwards. One way to test this hypothesis is by looking at the difference in electoral outcomes between 1865 and 1859 and its correlation with the change in the local franchise between 1868 and 1865.

We tackle the potential problem of endogeneity by instrumenting the change in the difference in the constituency electorate using the level of the electorate in 1832 and the population size in $1861 .^{16}$ These variables can then be used as instruments under the assumption that they are correlated with changes in the electorate but not directly correlated with subsequent changes in the outcomes.

\footnotetext{
${ }^{15}$ We have also estimated our models using the quasi-maximum likelihood fractional logit estimator of Papke and Wooldridge (1996). This estimator has the advantage that it deals with a dependent variable that may include 0 and 1 and the conditional expectations of a dependent variable given an exogenous variable is estimated directly. The results are similar to the OLS estimates we present in the paper and are presented in the supplementary material.

${ }^{16}$ This is equivalent in the fixed effects strategy to instrumenting using the interaction between the year dummy and the $\log$ (electorate 1832) and $\log$ (population 1861).
} 


\section{RESUlts}

We begin our analysis by focussing on how the change to the electoral rules affected party competition between the Liberals and Conservatives at the constituency level. This is an important aspect of the reform, since choices made by voters in this landmark election depended upon the menu of options available to them which, in turn, reflected the strategic choices made by candidates responding to their new electoral environment.

As seen in Table 5, only $63 \%$ of seats were contested by both parties in 1865, though this falls sharply in 1868, and in some constituencies the seats were shared without an electoral contest taking place. ${ }^{17}$ A key strategic choice facing parties was where to run their candidates (and where not to run them) thereby allowing parties to best target their resources. Moreover, upon entering an electoral contest a decision was made on how many candidates to run. Most constituencies in 1868 were multi-member districts, thus providing a strategic incentive for parties to run with more than one candidate. Moreover, in this way a candidate and his running mate would share the cost of electioneering. Doing so was not without risk, however. Voters were not constrained to cast their votes for the same party and split-ticket voting was common. Moreover, a party that had little chance of winning more than one seat ran the risk of splitting its vote between its candidates, thereby handing an advantage to their opponents, if running more than a single candidate.

We present our analysis in Table 7 which shows estimates for equations (1) and (2) when exploring the effect of the franchise extension on the ratio of candidates to seats, the share of seats that were uncontested in each constituency and, critically, the share of candidates at the constituency level who were Liberal.

The first effect we look at is the ratio of candidates to seats. The first column records the impact of the change in the log of the electorate on the change in this ratio between 1865 and 1868, the second column looks at the same outcome conditioned on the change in (the log of) constituency population as well. ${ }^{18}$ The ratio of candidates to seats increases and by more in those areas most affected by reform. Indeed our estimates in column 2 show that a 100\% increase in the registered electorate corresponds to a $29 \%$ rise in the ratio of the number of candidates running to seats available. ${ }^{19}$

Part of the effect that is recorded in columns 1 and 2 of Table 6 is due to the decrease in the number of uncontested seats. Indeed, our estimates in columns 3 and 4 show that a decrease in uncontested seats is causally related to the impact of the reform at the constituency level. The

\footnotetext{
${ }^{17}$ See Lloyd (1965) for a history of uncontested seats between 1852 and 1910.

${ }^{18}$ Recall that, since we restrict our sample to those constituencies where the number of seats remains the same, the difference within a constituency between 1865 and 1868 is driven by an increase in the number of candidates.

${ }^{19}$ Note that a $100 \%$ change in the franchise is equivalent to a change in the difference in logs, our causing variable, of around 0.693 (i.e., $\ln (2)$ ).
} 
estimate in column 4 suggest that a $100 \%$ increase in the registered electorate leads to a statistically significant $22 \%$ decrease in the share of uncontested seats. A key question is whether the overall increase in party competition is driven by greater contestation by Liberal candidates. Our estimates in columns 5 and 6 show that, not only is there an increase in party competition that can be causally related to the change in the electoral rules, but that this entire effect is driven by greater contestation by Liberal candidates. ${ }^{20}$ In short, our estimates show that more candidates ran in the areas most affected by reforms, and that these additional candidates stood under the Liberal label.

Did the increase in contestation by Liberal candidates supply an electoral advantage to the Liberals that can be related to the reforms? To answer this question we can explore how the reforms affected voting at the constituency level. We present our analysis in Table 8 which shows estimates for equations (1) and (2) when exploring the effect of the franchise extension on the constituency share of seats won by the Liberals, the Liberal share of the vote, and voter turnout. As before, the first column records the impact of the difference in the log of the electorate on the difference in the share of constituency seats won by the Liberals between 1868 and 1865, whilst the second column looks at the same outcome conditioning on the difference in (the logs of) constituency population. Perhaps surprisingly the effect of franchise extension is negative, small and statistically insignificant. For example, taking column 2, a $100 \%$ increase in the registered electorate leads to a $4 \%$ fall in the share of liberal seats. Columns 3 and 4 analyze whether there is any evidence relating the change in the constituency level franchise to the change in the Liberal share of the constituency level vote. The estimates are positive, as expected, but the magnitude of the effect is small and non-statistically significant. For example, in column 4, a 100\% increase in the registered electorate leads to a $4 \%$ increase in the Liberal share of the vote.

Finally, the fifth and sixth columns of Table 8 estimate the effect of franchise extension on voter turnout. Our estimates suggest that the difference in turnout between 1865 and 1868 is somewhat lower in areas where the impact of franchise extension was largest. When including a control for population change we find that the a $100 \%$ increase in the registered electorate corresponds with a $7 \%$ decrease in turnout, and thus an immediate consequence of changing the electoral rules was a slight dampen of turnout in those areas most affected by reform.

Combining the results in Tables 7 and 8 for the period 1865-1868, and once we account for a trend toward the Liberals that affects all constituencies, as well as constituency fixed traits, we are left with a stark conclusion: although the Liberals responded to the new electoral environment by increasing the number of candidates running and contesting more seats, this did not feed into

\footnotetext{
${ }^{20}$ The number of candidates, the numerator in the outcome for columns 1 and 2 , is the sum of candidates running under the liberal and conservative party labels. Therefore, if the denominator in columns 1, 2, 5 and 6 is the same for every election, the coefficient that results from regressing candidate to seat ratio against any time varying variable is identical to the sum of the coefficients that will result using liberal candidates to seat ratio and conservative candidates to seat ratio as outcomes. Thus, the coefficient on the franchise variable for the outcome conservative candidate to seat ratio is the difference between column 1 (2) and 5 (6).
} 
greater support for Liberal candidates or an increase in the Liberal vote share. Thus, although the Liberals were successful in winning the election in 1868 , the outcome is not causally related to the reform of the franchise introduced in 1867.

Probing further we ask whether this result is due to strategic considerations of candidates, influenced perhaps by party pressures, that arose as a result of the reforms. Was a perceived Liberal advantage in the electoral market nullified by the reaction of Conservative candidates?

The introduction to the franchise of a large number of unskilled workers may have affected the strategic choice of sitting incumbents whether to run again in the same constituency. A particular source of Tory disadvantage was that, as the party of the gentry, their established candidates may have been deemed out of touch with the concerns of the new electorate. It seems likely that such incumbents would be less inclined to run in those constituencies where franchise extension was largest. The replacement of these incumbents, with candidates more likely to be elected, may then have nullified a Liberal advantage.

Our estimates, shown in Table 9, confirm that the retention of incumbents decreases in those areas most affected by reform: for example in column 2, a $100 \%$ increase in the registered electorate in a constituency leads to a $21 \%$ reduction in the share of incumbents running for office. However, turning to columns (3) and (4) of Table 8 we observe, perhaps surprisingly, more than 70 percent of this effect is driven by the change in the share of Liberal incumbents.

In the remaining columns in Table 9 we explore the impact of reform on the attrition rate of candidates who had lost in the 1865 . We fail to reject the null hypothesis that the decision of a candidate who lost in 1865 to run in the same constituency in 1868 was unaffected by the impact of the electoral reform in the constituency. Though we note, from Table 5, that only $7 \%$ of candidates running in 1868 were losing candidates in 1865.

\section{Robustness CHECKS}

Our estimates do not show any conclusive evidence that the Liberal victory in 1868 was related to the change in rules governing the eligibility to vote in this election. Our findings suggest that, although the nature of the political contest between the Liberals and Conservatives would have been different if the old rules had remained in place in 1868 , the outcome would have been the same. In this section we assess how robust are our null findings.

7.1. Extending the sample of constituencies. We explore whether our results change when we consider different constituency samples. Redistricting is a politically charged issue, the more so in light of a major change in the vote eligibility requirements. For this reason, thus far, we restricted our sample to those boroughs not affected by boundary or other changes. One might expect, 
however, that Disraeli would leave untouched those constituencies where the Liberal vote was growing at a relatively lower rate, whilst tampering with the boundaries and district magnitude in other districts where the Liberal vote share was increasing. If this were true then this could indeed account for our null estimates in this restricted sample. To explore this issue we analyze a wider sample of constituencies and assess non-linearities in the effect of our causing variable.

In Panel A of Table 10 we assess estimates from a set of regressions based on a sample that excludes only those constituencies where district magnitude changed, (ie. we now include districts with boundary changes). In panel B we we use a wider sample still, including also those boroughs that received changes in the number of seats. In these regressions we account for non-linearities by allowing for interactions between the effect of extending the franchise to the local voting population and other aspects of the electoral law that changed simultaneously at the district level. For brevity we concentrate on the regressions that control for population change.

Our main results concerning the effect of franchise extension on the Liberal vote share or seat share are unchanged in Panel A: when assessing the wider sample of constituencies, including those with boundary changes, there is no direct effect of the difference in the local voting population upon either of these variables, and no systematic difference between constituencies according to whether they were affected by boundary changes or not.

In Panel B, when assessing the wider sample of constituencies, including those with boundary and/or changes to seats, an increase in the difference in the local voting population reduces the change in the liberal share of the vote. Moreover it does so in precisely those constituencies affected by boundary changes. The effect of an increase (difference) in the local franchise is not that expected if the hypothesis that Disraeli was able to strategically manipulate the Liberal vote were true. Whilst we would then expect that the difference in the Liberal vote share is greater in those areas where boundary and seat changes were implemented, the opposite is in fact true: our result shows a coincidence between those constituencies where the change in the franchise had a negative effect on Liberal performance and districts where the boundary commission altered the constituency contours. This evidence refutes the suspicion that Disraeli manipulated boundaries where Liberal support was growing at a relatively faster rate. And it offers confirmation that that our earlier null results are not an artefact of sample selection.

Turning to our other indicators of political competition, we find no evidence of an effect of changing the franchise in the estimates shown in Panel A. We find a direct effect on the Liberal share of candidates of a similar magnitude to that reported earlier. Similarly, we find that the difference in the constituency level franchise is associated with a decrease in the number of uncontested seats, and an increase in the candidate seat ratio. However here we show that this occurred in precisely those areas where there was a change to the number of district level seats available. 
7.2. Are the differences in $\mathbf{1 8 6 5 - 1 8 5 9}$ outcomes associated with franchise extension? As discussed earlier, a possible problem with our analysis occurs if the change in the constituency level electorate is systematically related to the growth in previous Liberal vote share in those constituencies. If this were so then we could not reasonably claim that the treatment is exogenously assigned; correspondingly, estimates derived from an analysis of equations (1) and (2) would be biased and inconsistent.

To analyze the validity of our assumption, we study the correlation between our key measure, difference in the log of the relative voting populations in 1865 and 1868, and the difference in outcomes between the 1865 election and the 1859 election. If the impact of franchise reform on the voting population was greater (smaller) in places where Liberal support was grew strongly (weakly) we would expect a positive (negative) association between the difference in outcomes in 1865-1859 and the difference in log electorates in 1868-1865.

In Table 11 we present the result of our analysis. For brevity we concentrate on the regressions that control for population change. Reassuringly, for our main measures of liberal strength, namely the Liberal share of the vote and the Liberal share of constituency level seats, the estimates are small and we are unable to reject the null hypothesis of no association between these variables. Furthermore, there is no evidence of a statistically significant association between the candidate seat ratio or the share of uncontested seats.

There is, however, a positive correlation between the difference in share of incumbents variables between 1865 and 1859 and the log difference in the electorate between 1868 and 1865. This association implies that the franchise grew by more in the constituencies where the share of liberal incumbents was higher. This is likely to bias upwards the effect of franchise extension on incumbency rates. Our instrumental variables results confirm this suspicion.

7.3. Instrumental variables estimates. An empirical strategy that can plausibly deal with biases that arise due to reverse causality, as well as those that are due to measurement error, involve the use of instrumental variables. We instrument the log difference in electorates using the (log) level of the electorate in 1832 and the (log) population size in 1861. These variables can be used as instruments under the assumption that they are correlated with changes in the electorate but not directly correlated with subsequent changes in the outcomes.

The first-stage was presented in Table 4, the F-test for the excluded variables is around 20. In Table 12 we replicate the analysis of Tables 6, 7 and 8 using our instruments. For brevity we concentrate on the regressions that control for population change. Our findings from Table 6 concerning the relationship between the extension of the franchise and differences in the nature of two-party competition at the constituency level continues to hold, though the estimates are now larger in magnitude: a $100 \%$ increase in the registered electorate leads to a $63 \%$ decrease in the 
share of uncontested seats and a $45 \%$ increase in the candidate to seat ratio, with almost all of this effect picked up by an increase in the number of Liberal candidacies.

In relation to the election results our conclusion remains unchanged. There is no evidence of a liberal advantage as a consequence of franchise extension. The increase in the franchise leads to a relatively small and still statistically insignificant increase in the liberal advantage. For example, a $100 \%$ increase in the franchise leads to an increase in the Liberal vote share of around $15 \%$ though this estimate is statistically insignificant.

The analysis in the previous sub-section highlighted an issue of concern in relation to the positive relationship between the difference in incumbency rates in 1865-1859 and the magnitude of franchise extension. As we predicted this was likely to bias downwards our estimates from Table 7. Our instrumental variables estimate suggest now that a doubling of the franchise leads to a $68 \%$ decrease in the share of seats contested by siting incumbents, of which around $62 \%$ is accounted for by non-contestation amongst Liberal incumbents.

It is worth pointing out that in all cases, we cannot reject the overidentifying assumptions at a 10 per cent level of statistical significance.

7.4. Long run effects of the reform. In Table 13 we analyze the political outcomes of the 1874 election with respect to those of 1865 and their relation to the constituency level difference in the voting population (1874-1865). This is a particularly interesting exercise not only because it allows us to see long run effects of the reform but also because the 1874 election is the first after the passing of the Secret Ballot Act (1872).

We find no effect, even in the longer term, of franchise extension on the Liberal share of the vote and the Liberal share of constituency seats. However, whilst we are unable to find a direct effect on our key indicators of Liberal strength, we again find evidence that the change in the electoral rules did affect party and candidate competition at the constituency level: a doubling of the franchise level lead to a $24 \%$ increase in the ratio of candidates to seats, a $20 \%$ reduction in contested seats at the constituency level and a $19 \%$ reduction in the share of seats contested by incumbents.

In contrast to our findings for the 1868 election, it appears that most of the increase in the candidate to seat ratio at the constituency level is driven by an increase in Conservative candidates. This finding is in line with the way historians have characterized the reaction of the Conservative party to the expansion of the voting population. As noted by St John (2006), in his biography of the Conservative leader, Disraeli realized that extension of the franchise placed an onus on effective party organization. He hired John Gorst to act as electoral agent of the party and as head of the new Conservative Central Office which provided a central register from which local Conservative associations could select candidates. In addition, local conservative associations were encouraged to form under the umbrella of a National Conservative Union. The net result was that in the 1874 
election the Conservatives were able to contest 63 previously uncontested Liberal seats. Indeed, and as shown by (Hanham, 1959), a key effect of the Reform Act was the development of national party organizations able to support country-wide candidacies and campaigning activities.

\section{Legislative Behavior and Franchise Extension: The Case of the Abolition of CHURCH RATES BiLL}

Whilst we have found that Tory incumbents, unlike their Liberal counterparts, were not less likely to run in those areas most affected by the extension of the franchise, electoral reform may have impacted their behavior in other ways. In particular, Conservative incumbents may have adapted their views in order to appeal to their new electorate. We should perhaps not overestimate the strength of the link between parliamentary activity and constituency level electoral behavior. Nevertheless, Mitchell and Cornford (1977) show that "the activities of MPs, particularly local MPs, were closely monitored in the local press" and provide evidence that local voting in Cambridge did reflect the parliamentary activities of representatives.

To explore this issue we turn our gaze away from our data concerning the electoral contest in 1868 and in previous years, to analyze the parliamentary voting behavior of Members of Parliament (MPs) in this period. We ask whether differences in the constituency level electorate that were related to franchise extension are related to differences in parliamentary voting behavior. ${ }^{21}$ Different empirical strategies could be deployed to detect changes in voting behavior that may, in turn, be related to the extension of the franchise. We might, for example, analyze the roll-call behavior of those Members of Parliament elected in both 1865 and 1868 to discern any differences across time in their voting record. Doing so would, however, yield biased estimates since the retention of incumbents in 1868 may reflect their voting record: a Conservative MP with a relatively liberal voting record in the period between 1865 and 1868, may have been elected by his new constituents because of his voting record. A related problem with analyzing voting behavior over different parliaments is that the historical record suggests that the agenda being voted on changed dramatically between the premierships of Derby and Disraeli on the one hand, and Gladstone on the other. The latter introduced a programme of reform in many areas of social and economic life far more radical than that of his predecessors. Differences in an MPs voting behavior may then simply reflect differences in what was on offer, rather than changes in his immediate constituency.

An alternative empirical strategy, that gets round these problems, is to assess the voting records of the same cohort of MPs before and after the introduction of the Second Reform Act and on the same set of bills. To this end, we focus our attention on the Abolition of Church Rates Bill introduced in the Parliamentary sessions of 1866 and 1867.

\footnotetext{
${ }^{21} \mathrm{~A}$ similar question is asked in recent work done on a different context by Gailmard and Jenkins (2009). They analyze roll-call behavior of US senators prior to and after the introduction of the 17th Amendment.
} 
Church rates were personal taxes on property owners that were used to support the established church. There was popular agitation to abolish them and support for abolition divided along religious and class lines: wealthier property owners tended to be members of the Church of England, vote Conservative, and supportive of the rates; by contrast, dissenters who opposed the tax tended to be found in the poorer sectors of the population. These divisions were found in both boroughs and Counties, with the latter described in following excerpt from Hansard:

"On the one side you have the supporters of the rate, the majority of the parishioners, including the squire, the clergy of the parish, and other residents, who in the County Directory are called the gentry. On the other side you have what, on the same authority, are called traders; you have the small farmers, the small village shopkeepers, and other persons in a lower grade of society. It is from this second class that the opponents of the church rate are mostly drawn."

In the Commons, votes on the bill divided along party lines also. The proposal to abolish rates had failed to pass second reading in 1865 under the Liberal government, with opposition from the Conservatives and some members of the Whig gentry aligned with the Liberals. It was introduced again in 1866 where it passed on second reading - by 285 votes to 252- despite Conservative opposition. Due to the constraints of the parliamentary timetable, the bill was not pushed through to third reading. The Abolition of Church Rates Bill was reintroduced in 1867, where it passed second reading with a larger majority. ${ }^{22}$

Two aspects are of immediate interest. The first is the difference in the outcome of the vote in 1866 and that of $1867 .^{23}$ In both cases the bill passed its second reading. However, in 1866 there were 252 "Noes", whereas, and by contrast, in 1867 there were only 187 (and 263 "Ayes"). A further aspect of interest is the timing of the 1867 bill. The second reading of the Abolition of Church Rates Bill was voted on in Parliament on March 15th, 1867, one month after the Queen's speech which anticipated a policy that "without unduly disturbing the balance of political power shall freely extend the electoral franchise," and Disraeli's reading of the Second Reform Act on the floor of the House. ${ }^{24}$ The question then arises whether MPs who had previously opposed abolition changed their behavior, by either voting in favor or abstaining from the final vote, when faced with an increase in opposition to the Bill amongst their constituents.

Table 14 tabulates the votes on the bill from our sample of 321 MPs that belong to boroughs who appear in all elections from 1859 to $1874 .{ }^{25}$ Of the 100 who voted "No" in 1866, 38 abstained in 1867. Out of 183 MPs who voted "Aye" in 1866, only 37 members abstained in 1867 . The largest

\footnotetext{
${ }^{22}$ The bill was rejected by the Lords and Church Rates were abolished by the new parliament in 1868 .

${ }^{23}$ Information for the 1866 and 1867 votes was obtained from http://hansard.millbanksystems.com/.

${ }^{24}$ The second reading in 1866 was voted on March 7.

${ }^{25}$ Of the 335 elected MPs in 1865 for our sample of 207 Boroughs, 14 members were either made peers, had their election declared void, resigned, or passed away.
} 
change is then in the number of MP's who, though voting "No" in 1866, chose to abstain in 1867 , where we define abstention as neither voting "Aye" or "No" in each particular vote.

Does the forthcoming increase in the franchise lead to a decrease in the likelihood of voting "No"? To answer this question, we coded a dummy variable 1 if the MP had voted "No" in 1866 and zero otherwise, a similar variable is coded for 1867 and we use their difference as the outcome of interest. As in our previous analysis we regress this outcome on the difference in (log) electorate between 1868 and 1865 at the constituency level. Estimates of this model, that are presented in Table 14, reveal in general negative but small and statistically insignificant effects of franchise extension on the voting behavior of MPs. The results are independent of whether we include controls for population change or look at samples that include constituencies that will suffer boundary changes or changes in the number of seats. ${ }^{26}$

\section{CONCLUSION}

The Second Reform Act of 1867, a major turning point in British history, is associated with the election of the first unequivocally Liberal government on a reforming agenda. The association between the reform, on the one hand, and the immediate electoral outcome, on the other, plays an important role as supporting evidence for an influential theory of electoral reform. Acemoglu and Robinson (2000) suggest that franchise extension was introduced to ameliorate pressure for more radical political and economic change. The fact that the reform was sponsored by the Conservative Party despite their subsequent defeat, and, more importantly, introduced in such a way that the vote increased by more in urban areas seen to be sympathetic to the Liberals, lends support to their theory. And yet, a careful investigation of the data does not support the claim that the 1867 reform benefited the Liberals in 1868 election and so casts doubt upon this evidence. Despite the significance of the Act, when controlling for a trend towards the Liberals that affects all constituencies, as well as local fixed traits, there is no evidence that the outcome of the 1868 election was in fact related to the change in the franchise rules.

It is possible that this result reflects the imprecise way in which franchise reform translated into the allocation of votes at the constituency level. Although the voting population increased dramatically as a result of the 1867 reform, the constituency level variation in the impact of the reforms reflects the workings of what Davis and Tanner (1996) call a "capricious system" that left many men who, in principle, were entitled to vote, nevertheless unable to. We show that, even when taking account of the uneven impact of the reforms that arose due to local difficulties in administrating the new franchise rules, the reforms had little impact on the Liberal vote share in 1868. Of course it is possible that the impact of the reforms was delayed. The full impact of the Second Reform Act may

\footnotetext{
${ }^{26}$ We condition on the difference in the number seats in columns (1) and (2). The results are similar when not conditioning on this difference.
} 
not have been felt until the administrative problems were ironed out and the number of registered voters, in the Metropolitan boroughs in particular, more closely approximated the eligible voting population. Our analysis casts doubt on this assertion: even when taking account of error in our measure of franchise extension, there is no discernable effect of the change in the rules upon the Liberal vote share.

It is implausible, however, that the Second Reform Act had no effect on the electoral and political outcomes in 1868. Indeed Cox (1987) shows that a large number of factors affecting the electoral connection between citizens and representatives changed in Victorian England. These included amongst other things the number of contested seats and the percentage of incumbents standing. We provide a similarly wide lense through which to investigate the effect of reforms and isolate the specific effect of changes to the franchise rules from broader trends and other confounding factors. The evidence clearly shows that the major impact of the franchise extension was in increasing political competition at the constituency level: more seats became open to contestation and this effect is causally related to a change in the franchise rules. Initially the Liberal party were well placed to take advantage, running more candidates in those areas where the franchise increased by the most. Over the longer term (1865-74) it was the Conservative Party that were quicker to adapt, by developing their local organizations in those boroughs were the franchise effects were largest. A key lesson for political scientists that emerges from our analysis is that the effect of electoral reform, whilst not immediately observable in the subsequent electoral outcomes, operates via different channels of party competition.

\section{REFERENCES}

Acemoglu, D. and J. A. Robinson (2000). Why did the west extend the franchise? democracy, inequality, and growth in historical perspective. The Quarterly Journal of Economics 115(4), 1167-1199.

Aidt, T. S., M. Daunton, and J. Dutta (2009). The retrenchment hypothesis and the extension of the franchise in england and wales. Forthcoming The Economic Journal.

Aidt, T. S. and P. S. Jensen (2009). The taxman tools up: an event history study of the introduction of the personal income tax. Journal of Public Economics 1-2, 160-175.

Boix, C. (2001). Democracy, development and the public sector. The American Journal of Political Science 45(1), 1-17.

Boix, C. (2003). Democracy and Redistribution. New York: Cambridge University Press.

Bowley, A. (1937). Wages and Income in the United Kingdom since 1860. Cambridge: Cambridge University Press.

Cox, G. (1987). The Efficient Secret: The Cabinet and the Development of Political Parties in Victorian England. Cambridge: Cambridge University Press. 
Craig, F. (1989). British Parliamentary Election Results, 1832-1885, 2nd edition. Aldershot: Parliamentary Research Services.

Davis, J. and D. Tanner (1996). The borough franchise after 1867. The Historical Journal 69(2), 306-327.

Gailmard, S. and J. D. Jenkins (2009). Agency problems, the 17th ammendment, and representation in the senate. American Journal of Political Science 53(2), 324-343.

Gash, N. (1953). Politics in the Age of Peel: A Study in the Technique of Parliamentray Representation. London: Longmans Green.

Hanham, H. (1959). Elections and party management. London: Longmans Green.

Himmelfarb, G. (1966). The politics of democracy: The english reform act of 1867. Journal of British Studies 6, 97-138.

Husted, T. and L. Kenny (1997). The effect of the expansion of the voting franchise on the size of government. Journal of Political Economy 105, 54-83.

Jenkins, R. (1996). Gladstone: A Biography. San Val.

Lindert, P. (2004). Growing Public: Social Spending and Economic Growth since the Eighteenth Century, Volumes I and II. New York: Cambridge University Press.

Lindert, P. H. (1994). The rise of social spending, 1880 - 1930. Explorations in Economic History $31,1-37$.

Lizzeri, A. and N. Persico (2004). Why did the elites extend the suffrage? democracy and the scope of government, with an application to britain's age of reform. The Quarterly Journal of Economics 119(2), 707-65.

Lloyd, T. (1965). Uncontested seats in british elections. The Historical Journal 8(2), 260-265.

Mackenzie, W. (1921). Changes in the standard of living in the uk, 1860-1914. Economica (3), 211-230.

Maclean, I. (2001). Rational Choice and British Politics. An Analysis of Rhetoric and Manipulation from Peel to Blair. Oxford: Oxford University Press.

Mitchell, J. and J. Cornford (1977). The political demography of cambridge. Albion: A Quarterly Journal Concerned with British Studies 9(3), 1832-1868.

Papke, L. E. and J. Wooldridge (1996). Econometric methods for fractional response variables with an application to 401(k) plan participation rates. Journal of Applied Econometrics 11, 619-632.

Scheve, K. and D. Stasavage (2008). The conscription of wealth: Mass warfare and the demand for progressive taxation. Working Paper.

Seymour, C. (1915). Electoral Reform in England and Wales. New Haven: Yale University Press.

St John, I. (2006). Disraeli and the Art of Victorian Politics. Anthem Press.

Vincent, J. (1968). Pollbooks: How Victorians Voted. Cambridge: Cambridge University Press.

Vincent, J. and M. Stenton (1971). McCalmont's Parliamentray Poll Book, 8th edition. Harvester.

Whitfield, R. (2001). The Extension of the Franchise, 1832-1931. Oxford: Heineman. 


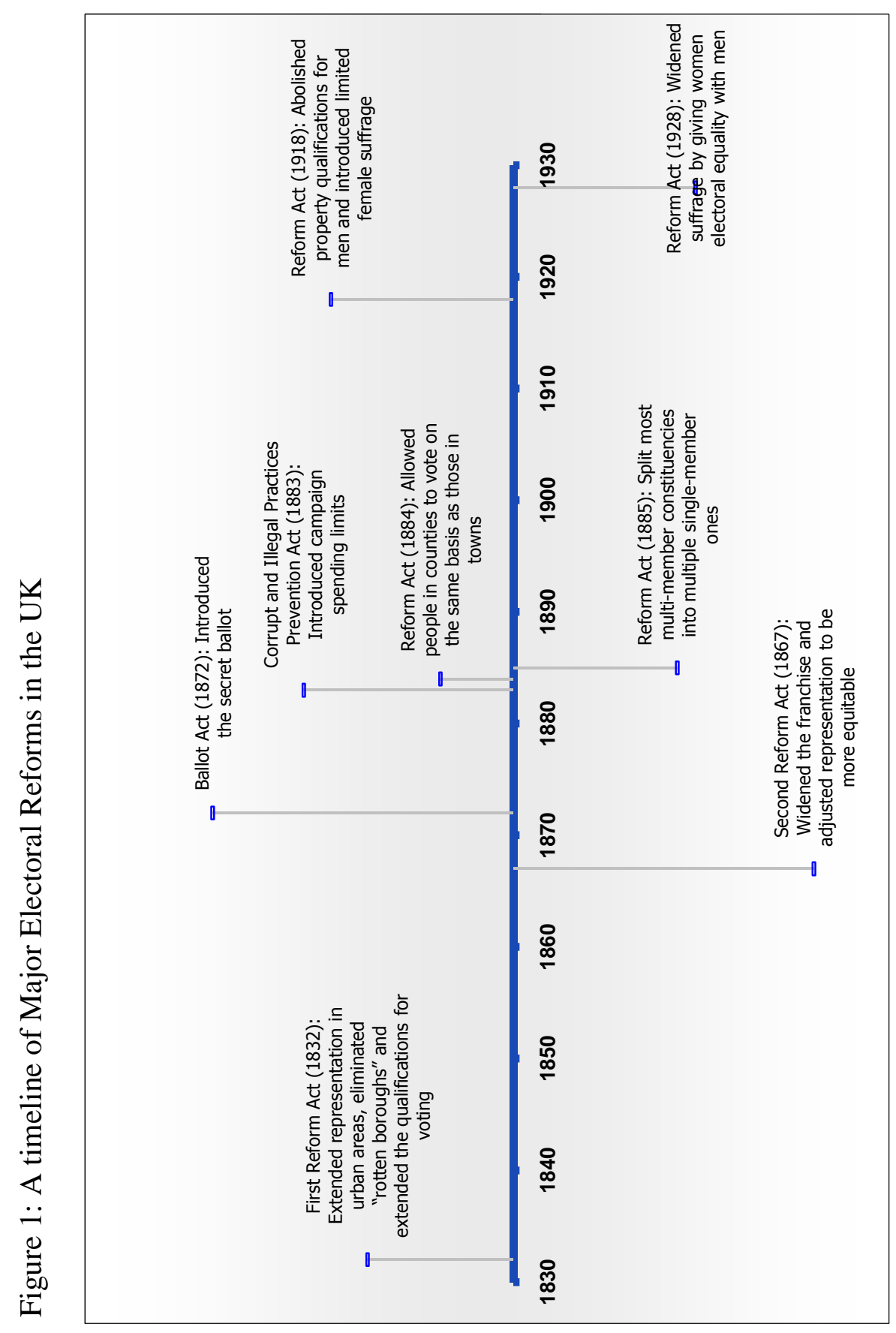






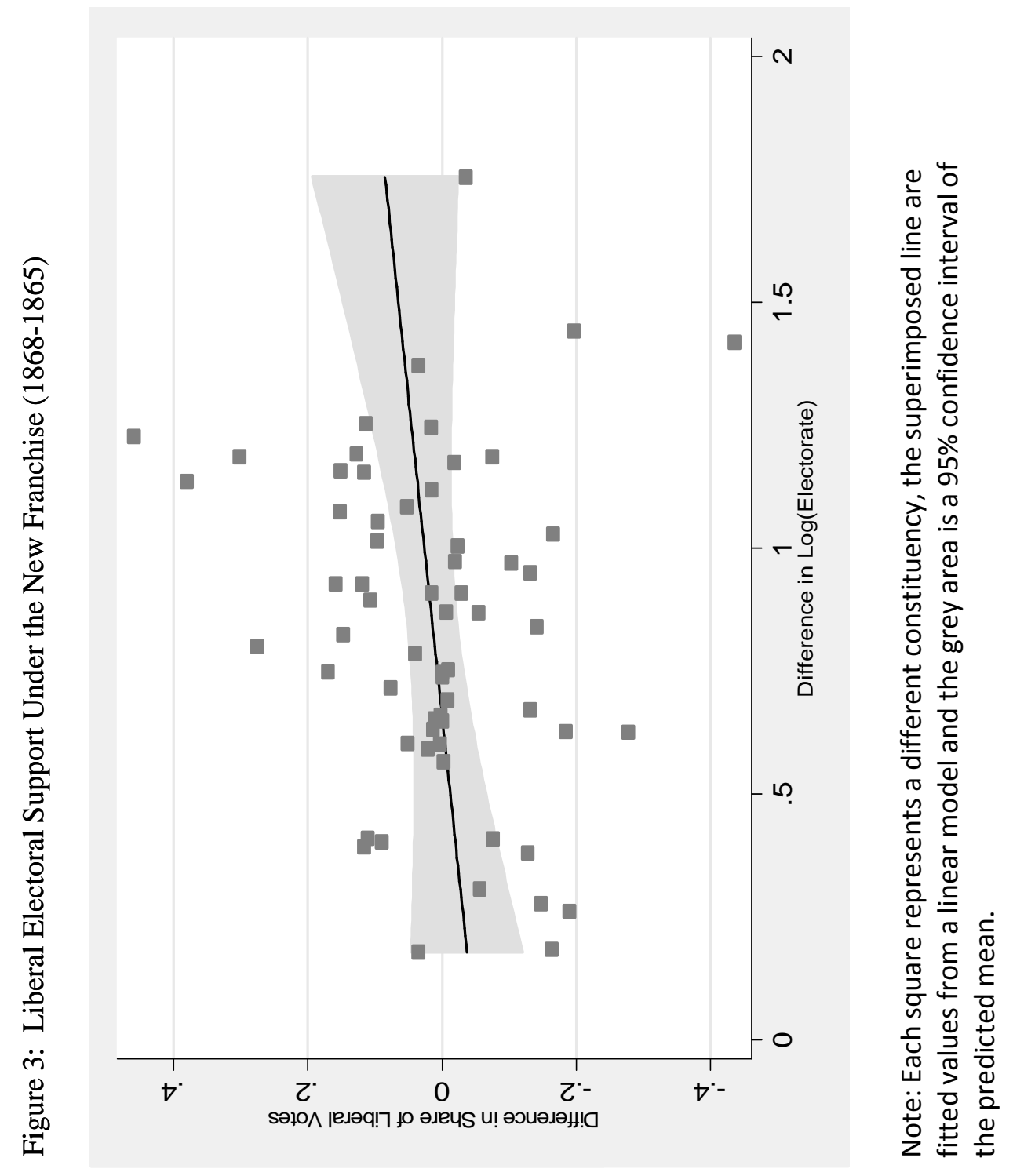




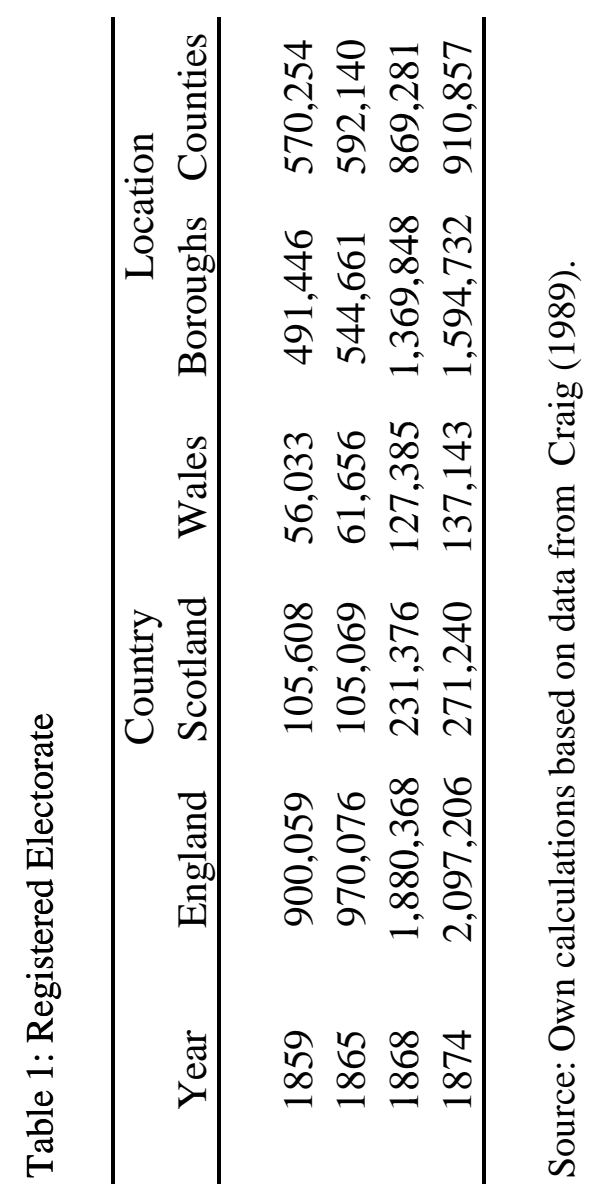




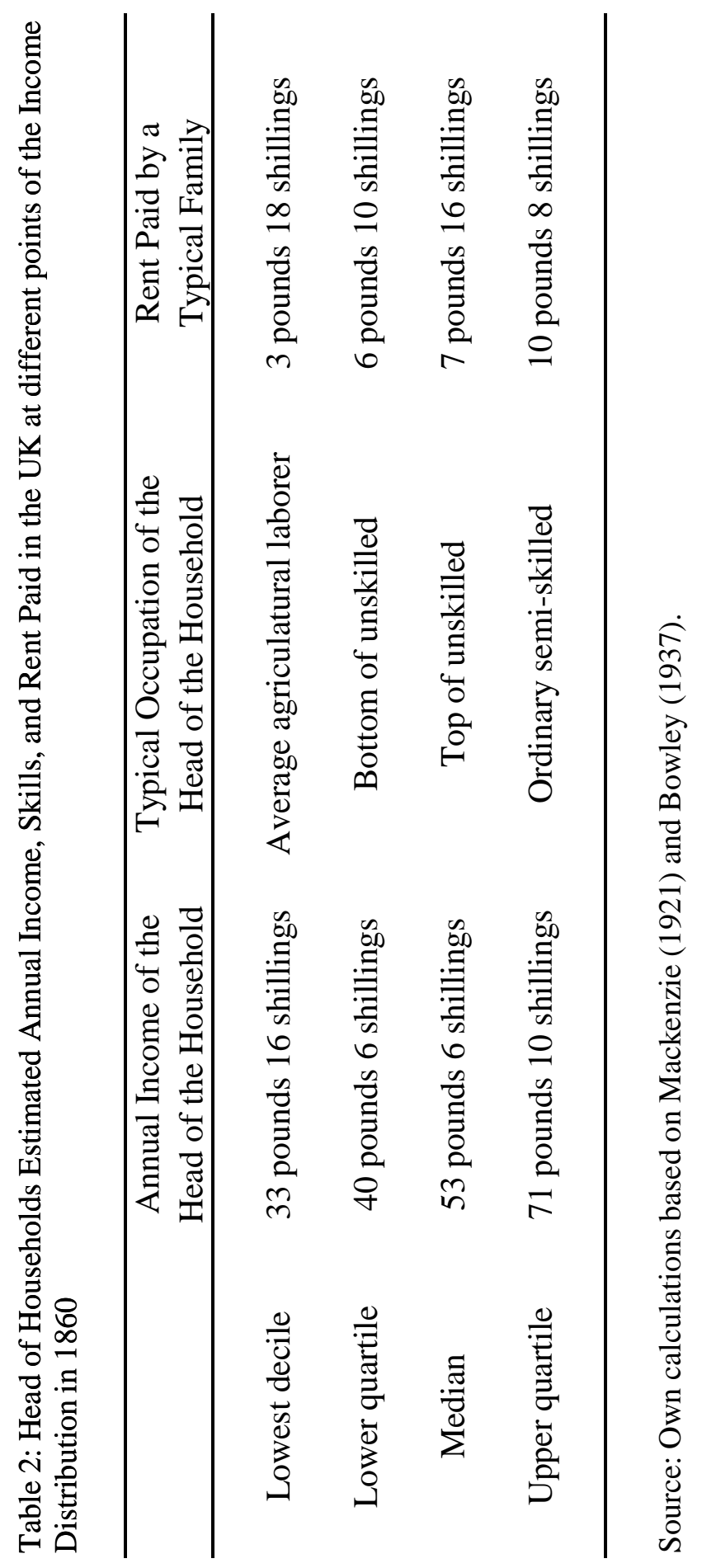




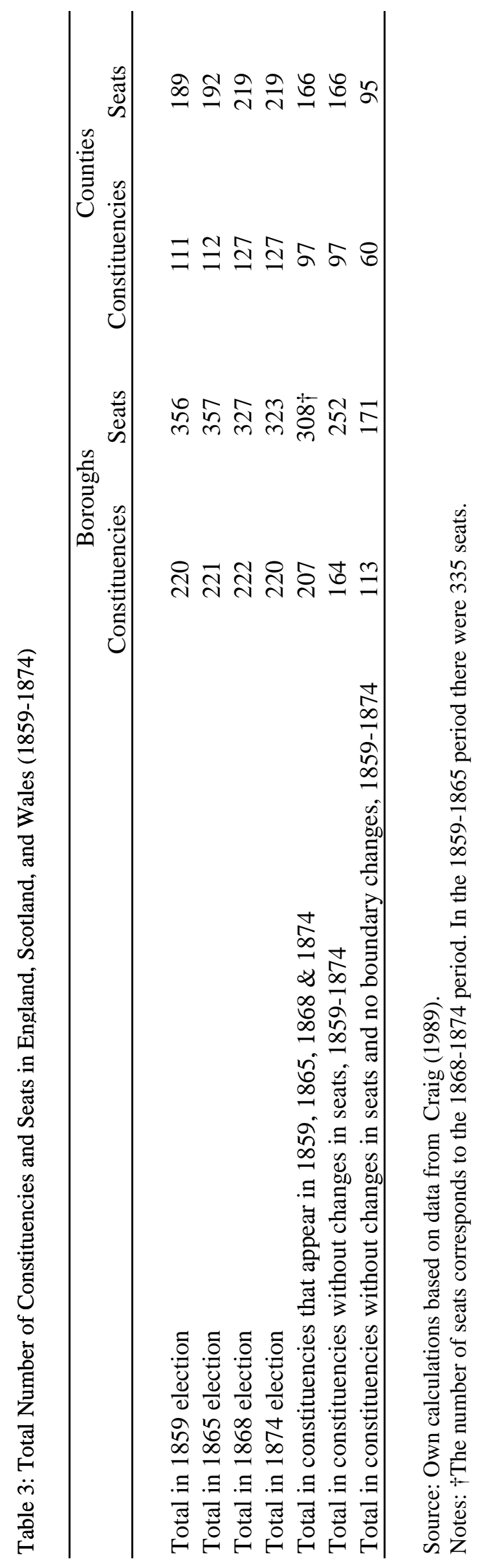




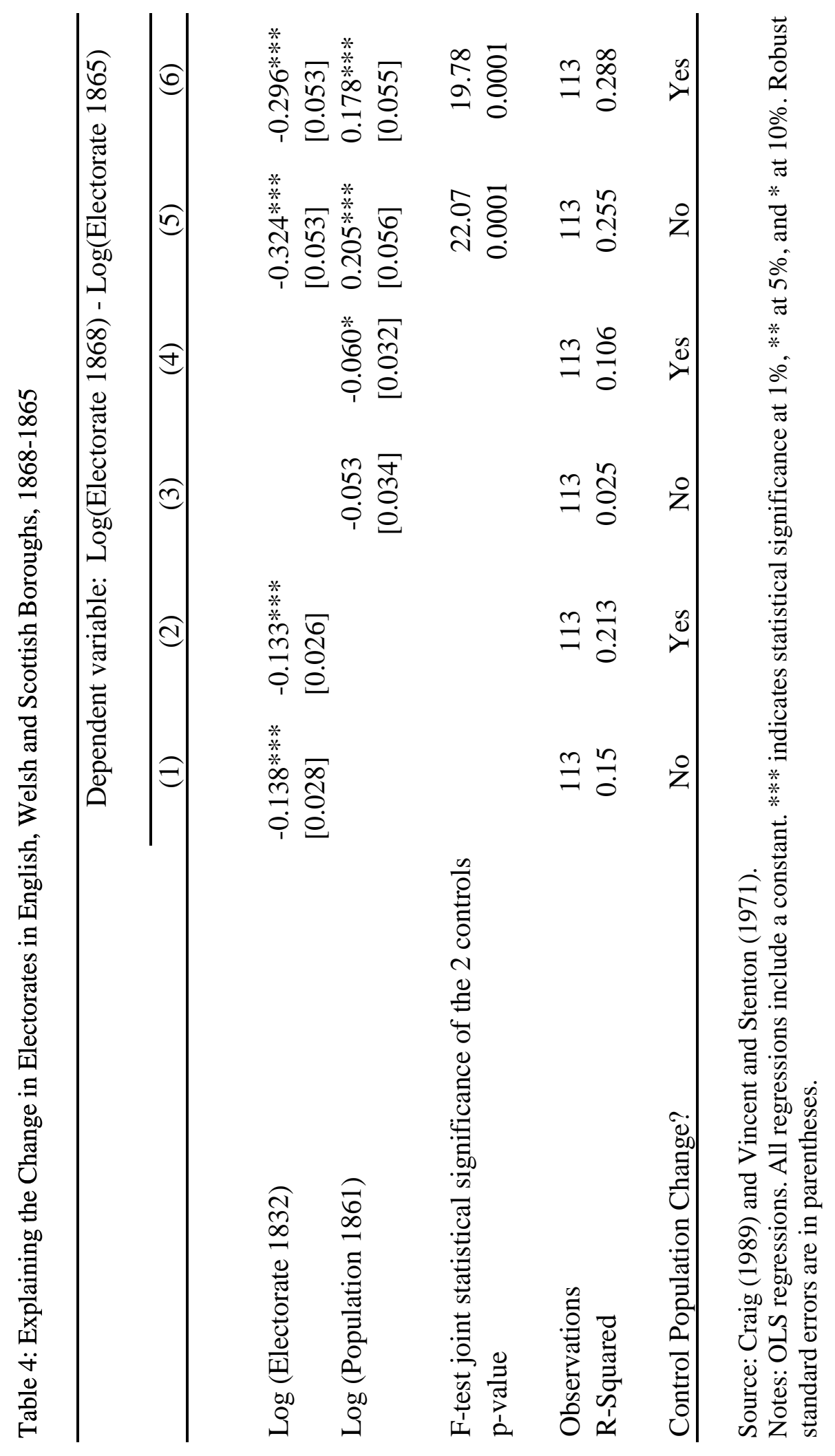




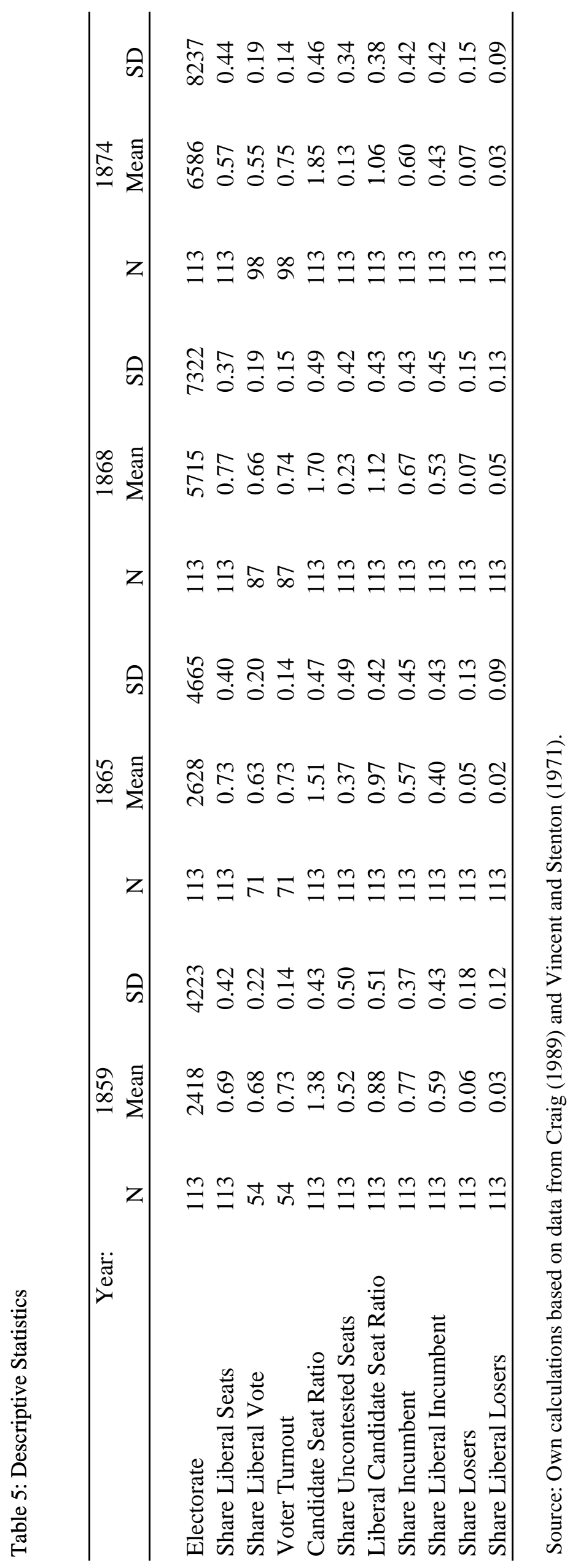




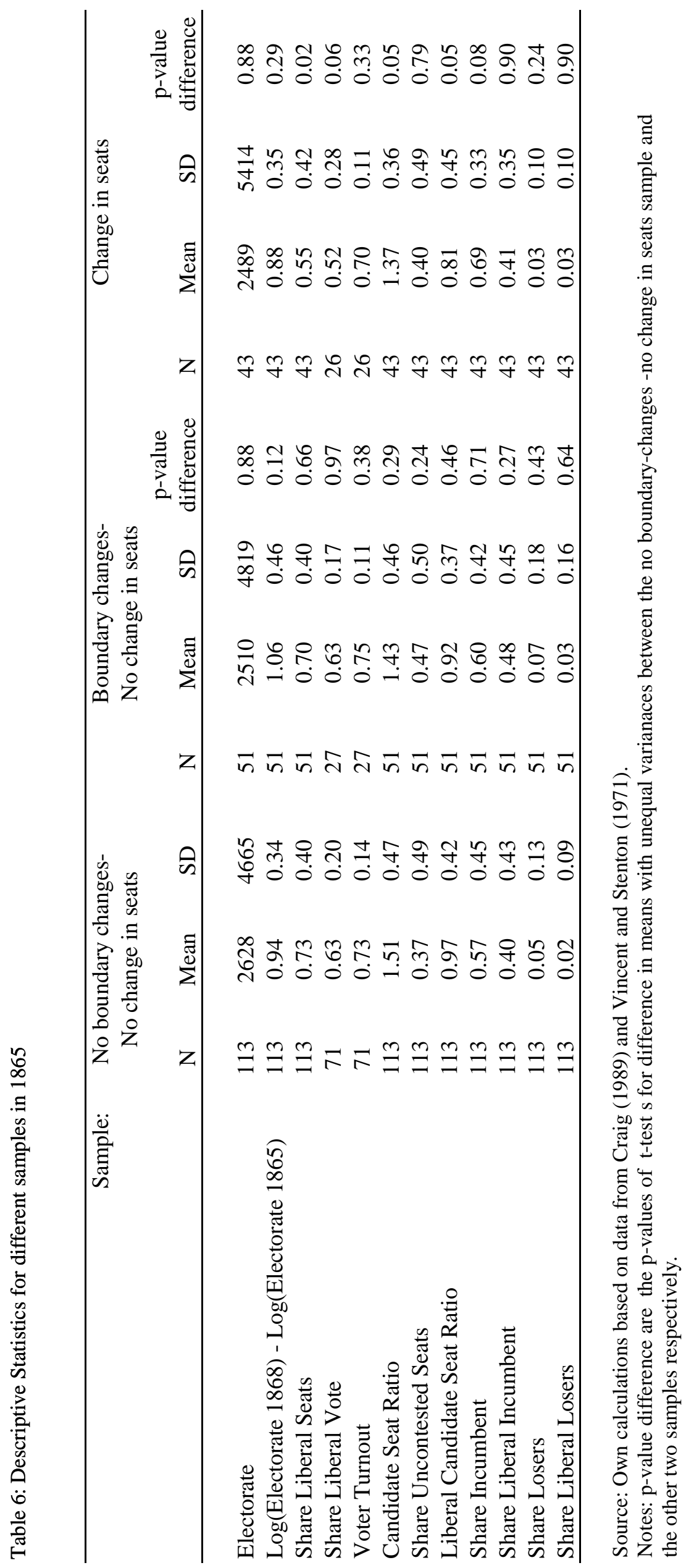




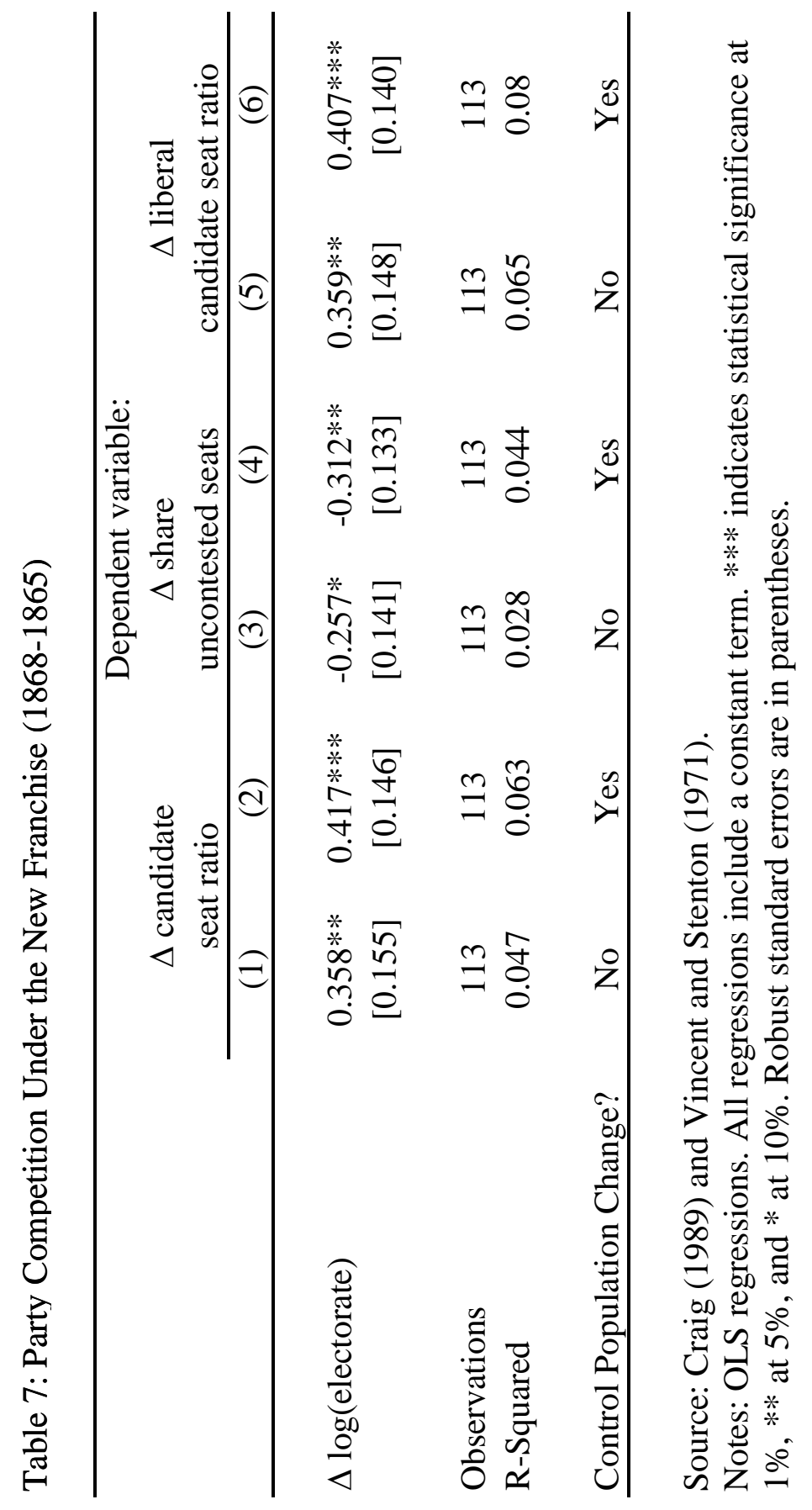




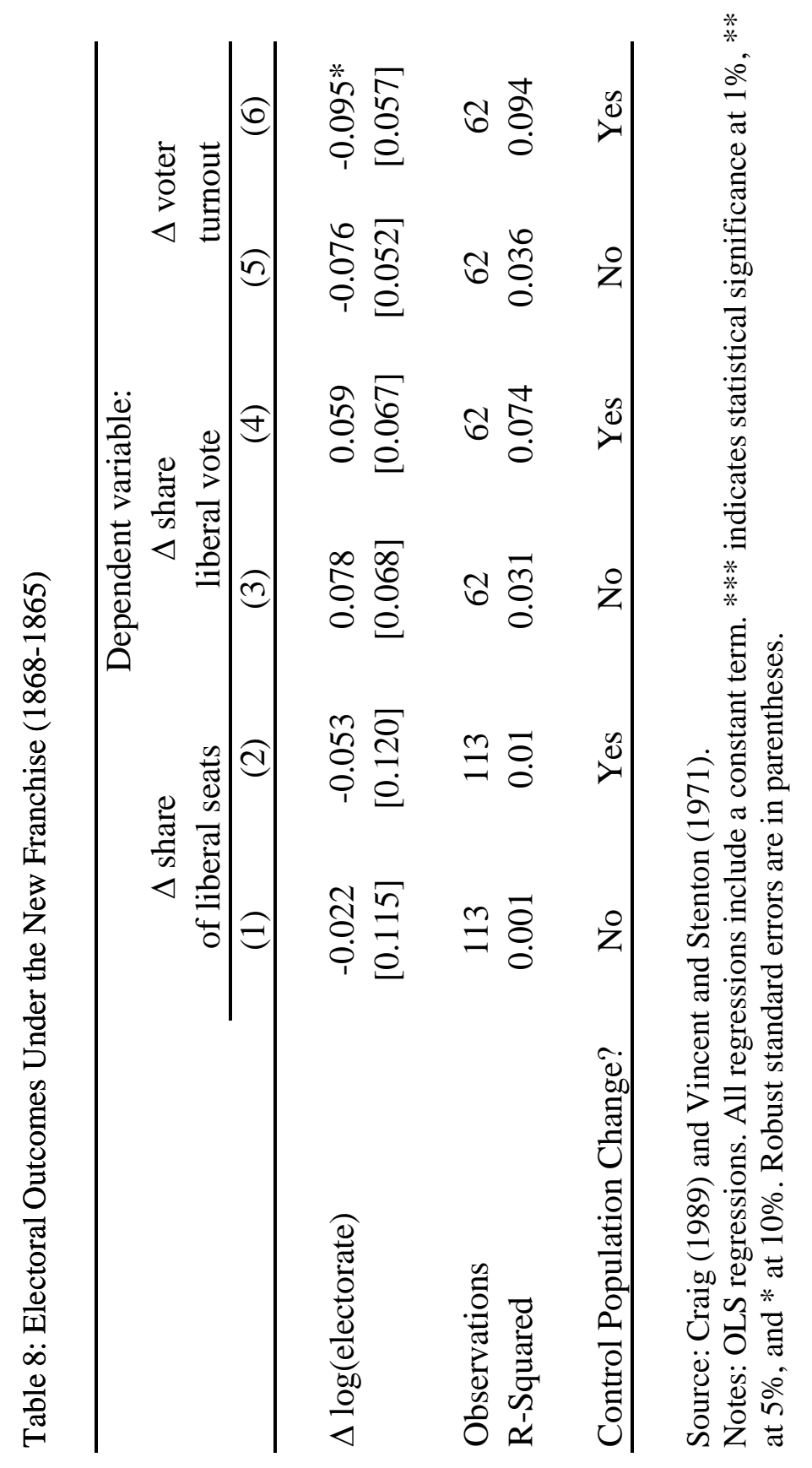




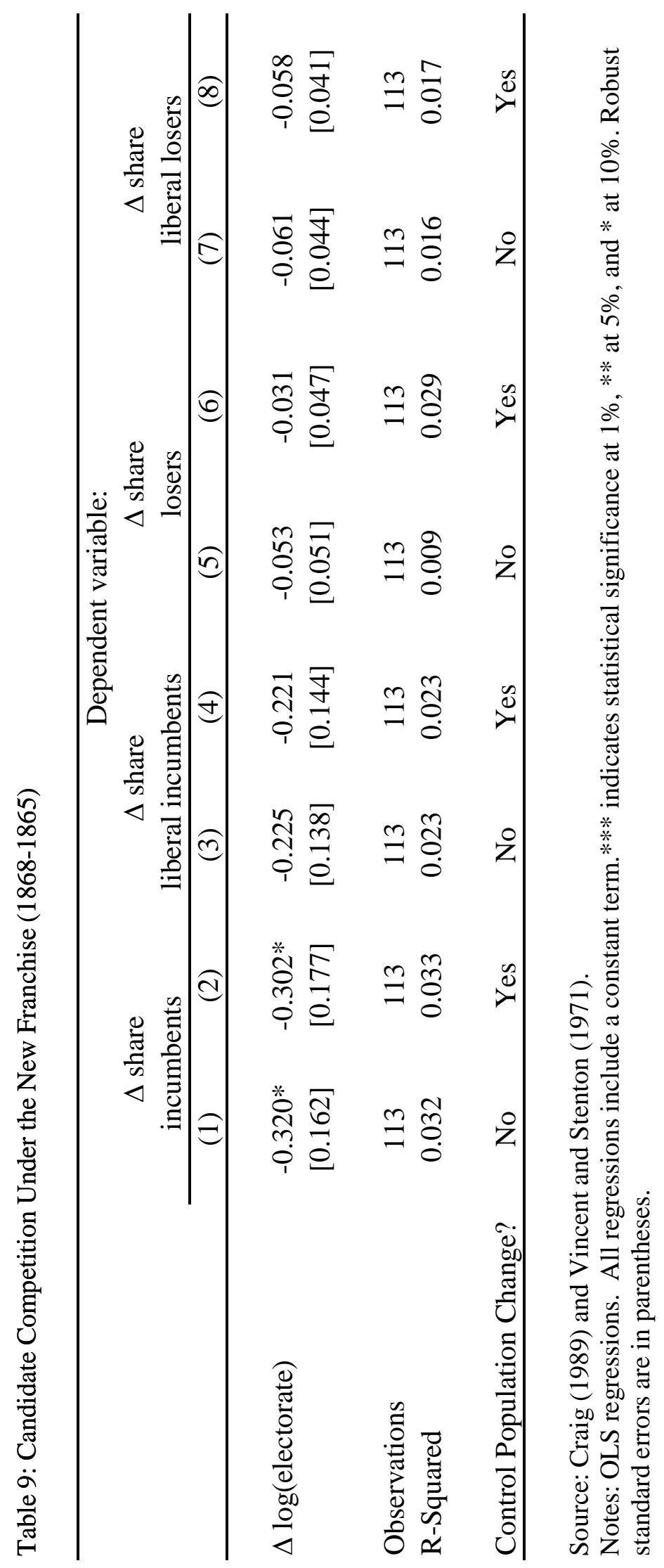




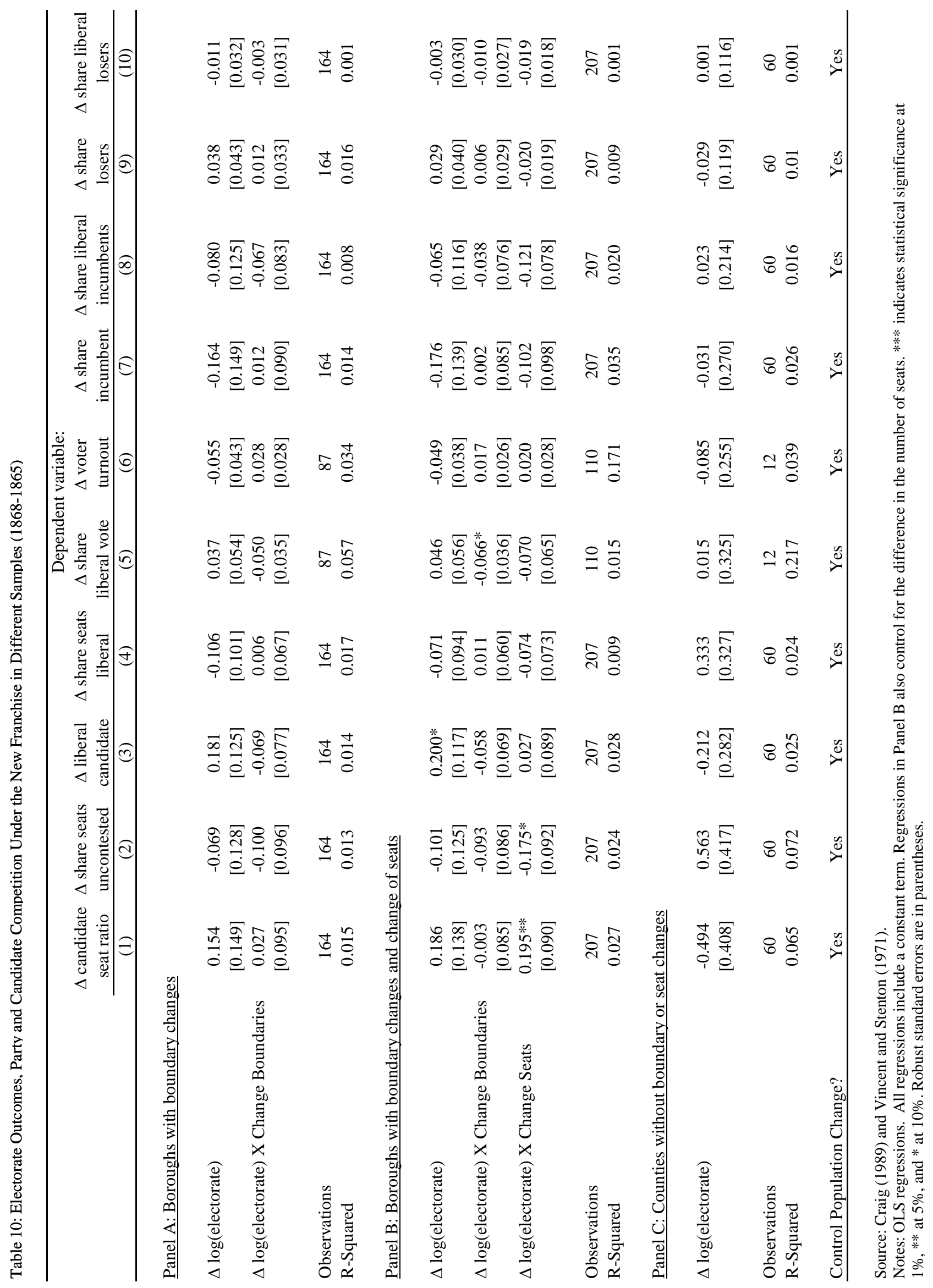




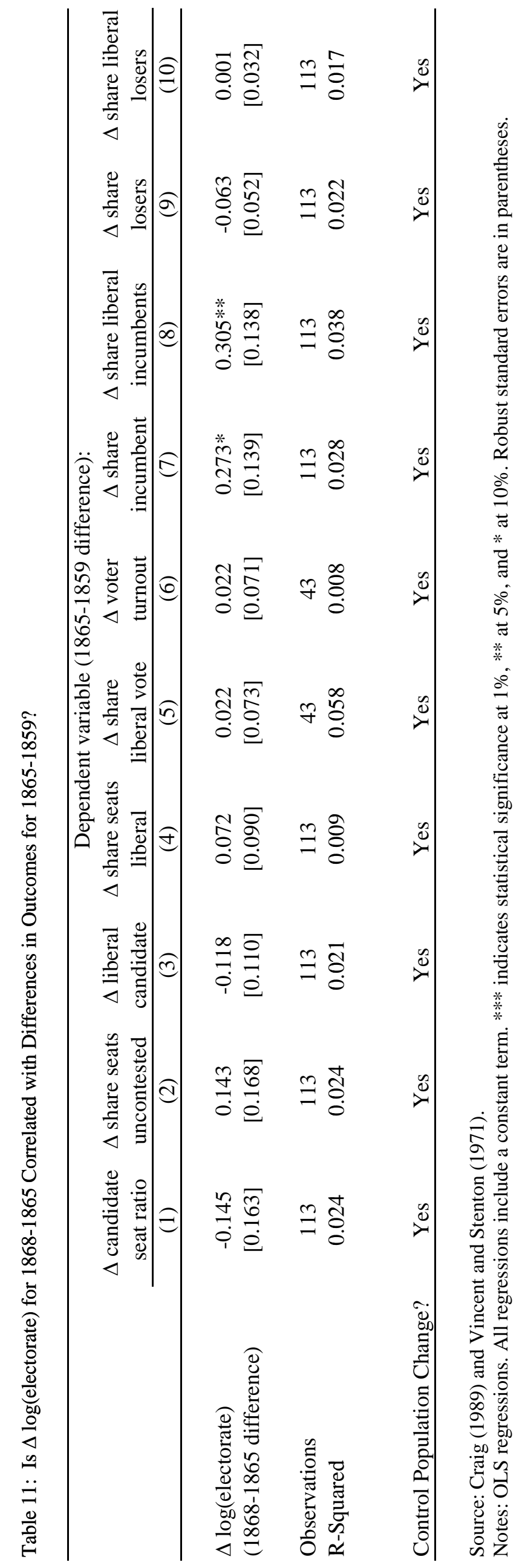




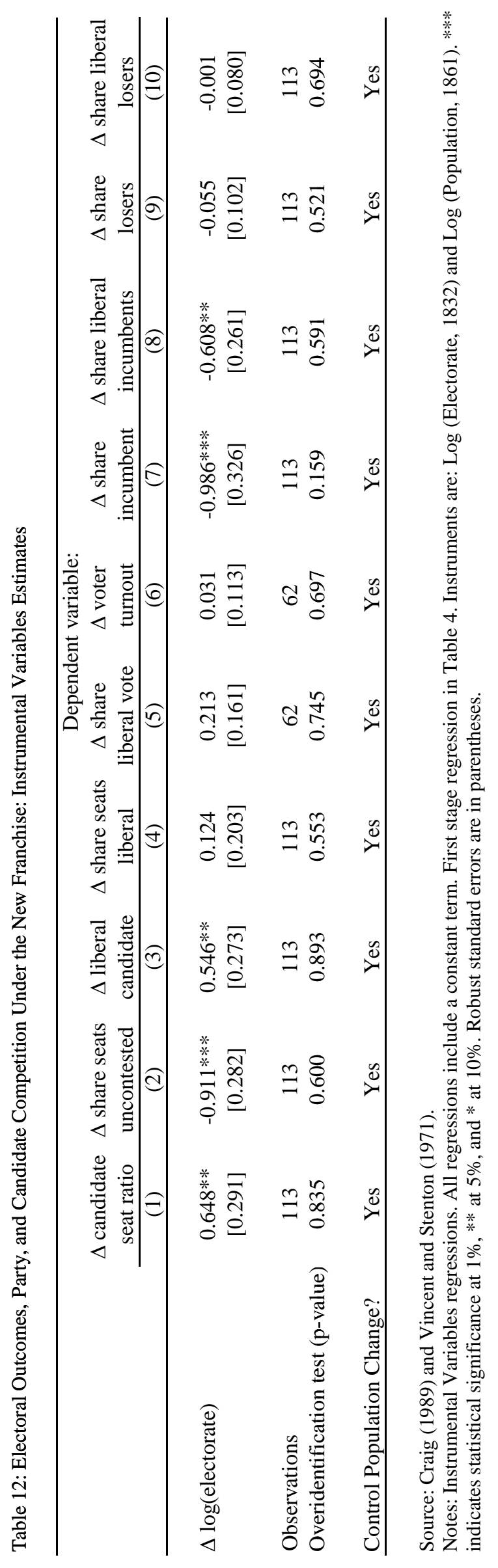




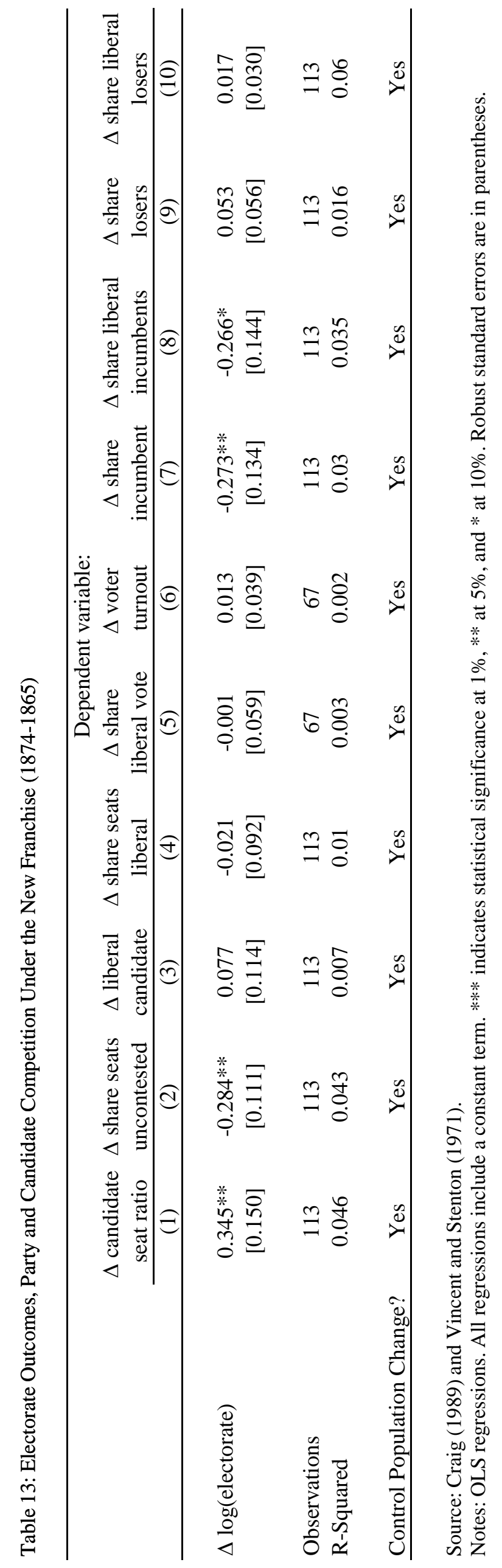




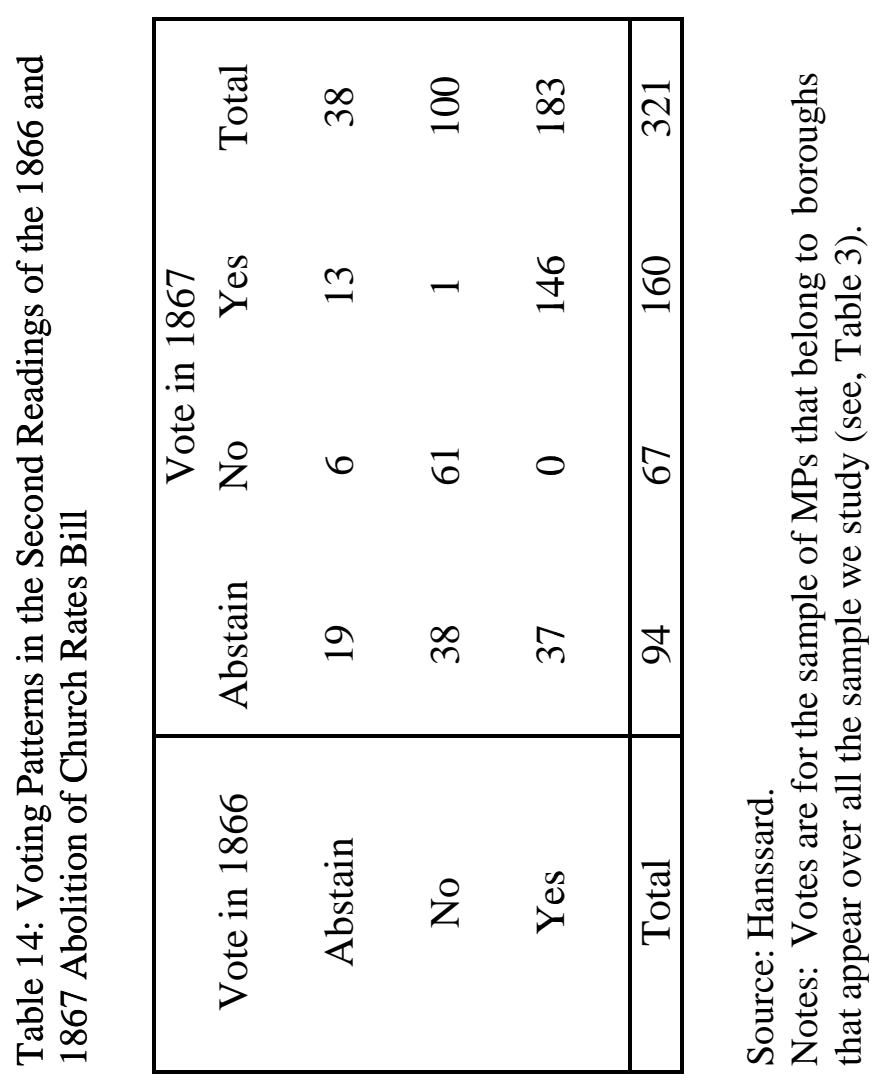




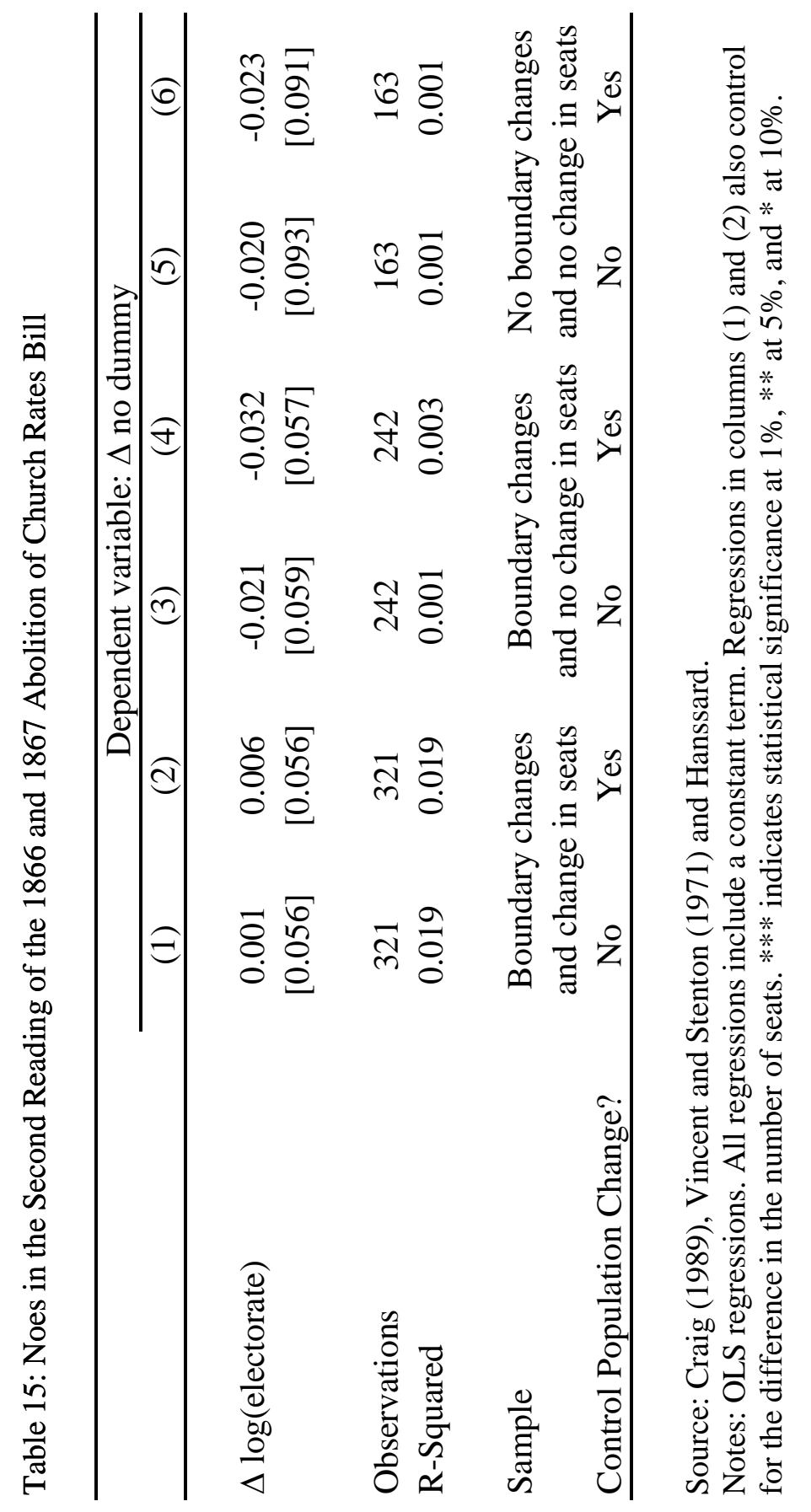

